\title{
Finite Element Analysis of CFRP Strengthened Bundle RC Column Subjected to Repeated Impact Load
}

\author{
Abreha Abay (1) \\ Department of Civil Engineering, Institute of Technology, Debre Berhan University, Debre Berhan 445, Ethiopia \\ Correspondence should be addressed to Abreha Abay; aabay3013@gmail.com
}

Received 24 September 2021; Accepted 8 January 2022; Published 8 February 2022

Academic Editor: Marco Filippo Ferrotto

Copyright (c) 2022 Abreha Abay. This is an open access article distributed under the Creative Commons Attribution License, which permits unrestricted use, distribution, and reproduction in any medium, provided the original work is properly cited.

\begin{abstract}
This paper studied numerically the behavior of carbon fiber reinforced polymer (CFRP) confined bundle reinforced concrete (BRC) columns subjected to repeated impact load. To verify the numerical models with previous experimental tests, Abaqus/ Explicit based nonlinear finite element (FE) model was developed. Based on the proposed FE analysis, a parametric study was conducted to investigate the effects of different factors such as CFRP confinement, eccentric axial load, bundle reinforcement arrangement, and column height on repeated impact capacity of RC column. While modeling the structural element, concrete damage plasticity (CDP) model is adopted to account for the plastic and strain rate-dependent behaviors of concrete material under impact load. From the nonlinear FE analysis result, it was found that CFRP confinement improved the impact capacity of bundle reinforced concrete column. As column height increased, the column impact resistance was found to decrease. Moreover, when the CFRP strengthened BRC column specimens were repeatedly impacted, the continuous matrix material was severely damaged, while the fiber showed only minor and gradual compressive failures.
\end{abstract}

\section{Introduction}

Impact phenomena cover a wide range of applications. A military engineer wants to design strong military works that withstand high-velocity projectiles, vehicle manufacturers require improving the efficiency and safety of their product by understanding how it behaves under impact scenario, and most importantly structural engineer needs to design stable and cost-effective structural elements that resist impact load safely. Concerning this, nowadays advancements in computational tools provide accurate and reliable numerical simulations of dynamic loads such as impact load over the limited empirical and complex analytical methods.

Carbon fiber reinforced polymer (CFRP) is a polymer matrix composite material reinforced by discontinuous carbon fibers (see Figure 1). CFRP has significant advantages including high strength to weight ratio, corrosion and fatigue resistance, and ease of implementation. Due to its superior mechanical properties, CFRP is the best material in strengthening and/or retrofitting different structural elements.

Taiping and Hamid [1] conducted an experimental test on FRP laminate retrofitted RC beams subjected to impact load. The drop weight impact test results presented that the FRP composite laminate significantly increased the impact capacity of the RC beams by reducing the residual deflection and width of the crack. Isaac et al. [2] performed an experimental test to investigate the effect of FRP on the impact response of RC column. It was found that strengthening of $\mathrm{RC}$ column with CFRP reduces the peak impact displacement. Sha and Hong [3] studied pendulum impact test of CFRP strengthened RC pier. Their results reveal that the application of CFRP composite wrapping on the RC pier improves the impact load capacity by increasing impact resistance and reducing structural damage. Liu and Xiao [4] examined the impact behaviors of CFRP strip-wrapped RC beams without stirrup. Their result showed that CFRP retrofit enhances the impact resistance of $\mathrm{RC}$ beams by reducing their deflection and limiting the damage profile. 
Dabbagh and Nosoudi [5] investigated numerical analysis of circular, square, and rectangular cross section RC columns confined with CFRP sheets. According to their study, they had found that an increasing CFRP thickness enhances the load-carrying capacities of the RC column. Hou et al.[6] found that strengthening of RC beam with CFRP changes the impact brittle mode failure to ductile. Zhang and Hong [7] reported that, at the same impact energy, FRP wrap improved the impact performance of mid-span and bottom segmental joint impact.

Based on the aforementioned information, the impact problem is a challenging topic for researchers, and hence it is clear that the study on impact performance of the BRC column is limited. In developing countries, compared to the finite element analysis, conducting an experimental study is a typically expensive and time-consuming task. Therefore, the need is evident to investigate numerically the impact performance of CFRP strengthened BRC column subjected to lateral impact load.

In this study, the effect of different parameters such as CFRP, bundle reinforcement, eccentric axial load, and column height on the repeated impact capacity of BRC column was investigated. Moreover, an explicit FE model was developed to verify the numerical model by comparing it with the previous experimental test result.

\section{Finite Element Analysis}

2.1. Description of the Study. The accuracy of the numerical modeling was validated by using previous experimental tests conducted by Yanyan and Hong [3]. Then, to understand the impact behavior of RC columns, several $400 \times 400 \mathrm{~mm}^{2}$ square column specimens have been modeled. The effect of different variables, namely, CFRP confinement, four different bundle reinforcement distributions (i.e., normal (BC-1), two bundles (BC-2), three bundles (BC-3), and four bundles (BC-4)), four eccentric axial loads (refer to Figure 2(a)), and three different column heights, was investigated. To identify the parameters easily, during FE simulation, the RC column specimens are nominated as in Figure 2(b).

2.2. Finite Element Discretization. The numerical model was simulated using Abaqus/Explicit package nonlinear FE analysis. As shown in Figure 3, concrete material was modeled using a 3D eight node linear brick element with reduced integration (C3D8R). Two-node linear 3D truss (T3D2) elements were implemented for the steel reinforcement bar. Similarly, the CFRP, epoxy risen, and lateral impactor were also modeled with a 4-node shell element (S4R), 8-node 3D cohesive element (COH3D8), and four-node 3D bilinear rigid quadrilateral (R3D4) elements, respectively. Moreover, the surface to surface explicit contact algorism was employed for the RC column and impactor interaction. Finally, a perfect bond was assumed to be the interaction between concrete (i.e., host region) and reinforcement bar (i.e., embedded region).

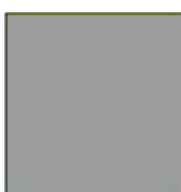

Matrix

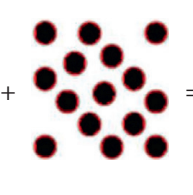

Fiber

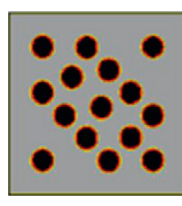

CFRP
Figure 1: Constituents of composite material.

\subsection{Material Model}

2.3.1. Concrete. $400 \times 400 \mathrm{~mm}^{2}$ square $\mathrm{RC}$ column with different bundle reinforcement distributions was modeled in Abaqus/Explicit. A concrete grade having a compressive strength of $38 \mathrm{MPa}$ was considered [8]. While simulating the numerical models, to account for the elastic-plastic behavior of concrete material, the concrete damage plasticity model (CDP) was employed. The CDP model is a plasticity based constitutive model that requires defining strain rate decomposition, stress stain relation, stiffness degradation mechanisms associated with each failure mode, hardening rule, flow rule, and stiffness recovery effects during load reversals. As shown in Figure 4, it is considered that the main failure mechanisms of concrete are tensile cracking and compressive crushing [9].

For strain-dependent models in CDP formulation, the total strain rate is usually assumed to be the sum of elastic and plastic strain rates as described in

$$
\dot{\varepsilon}=\dot{\varepsilon}^{e l}+\dot{\varepsilon}^{p l},
$$

where $\dot{\varepsilon}$ is total strain rate, $\dot{\varepsilon}^{e l}$ is the elastic strain rate, and $\dot{\varepsilon}^{p i}$ is the plastic part of the strain rate. The general stress-strain relationship of concrete in the CDP model can be expressed using

$$
\sigma_{t}=D_{o}^{e l}\left(1-d_{t}\right)\left(\varepsilon_{t}-\varepsilon_{t}^{p l}\right) \cdot \sigma_{c}=D_{o}^{e l}\left(1-d_{c}\right)\left(\varepsilon_{c}-\varepsilon_{c}^{p l}\right),
$$

where $\sigma$ is stress tensor, $\varepsilon$ is the strain tensor, $\varepsilon^{p l}$ is the plastic strain tensor, $D_{o}^{e l}$ is the initial (i.e., undamaged) elastic stiffness, $d$ is scalar stiffness degradation variable, and the subscripts $t$ and $c$, respectively, refer to the tension and compression zones of concrete.

(1) Concrete Compressive Behavior. The CDP model allows defining of the uniaxial compressive behavior of concrete in terms of inelastic (crashing) strain, $\widetilde{\varepsilon}_{c}^{i n}$. This compressive strain can be defined as the total strain $\left(\varepsilon_{c}\right)$ minus the elastic strain $\left(\varepsilon_{o c}^{e l}\right)$ corresponding to the undamaged material, given by

$$
\widetilde{\varepsilon}_{c}^{i n}=\varepsilon_{c}-\varepsilon_{o c}^{e l}=\varepsilon_{c}-\frac{\sigma_{c}}{D_{o}} .
$$

After determining the inelastic strain and damage parameter, Abaqus automatically converts these values to plastic strain using

$$
\widetilde{\varepsilon}_{c}^{p l}=\widetilde{\varepsilon}_{c}^{i n}-\frac{d_{c} \sigma_{c}}{\left(1-d_{c}\right) D_{o}} .
$$




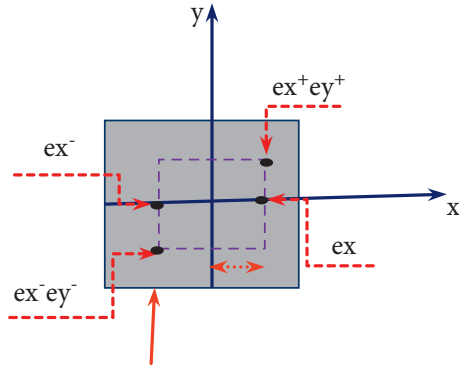

Column cross section

(a)

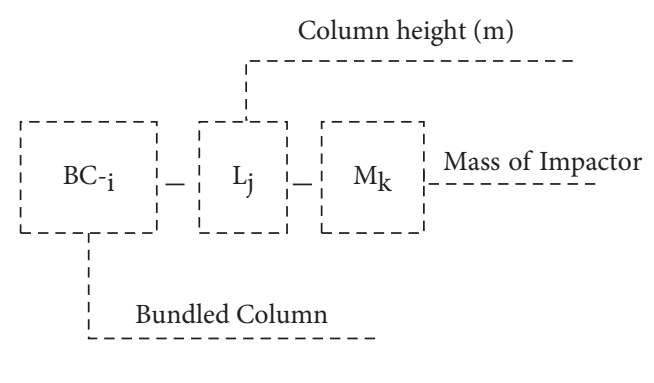

(b)

Figure 2: FE model parameter description: (a) locations of eccentric axial loads; (b) study specimen nomenclature.

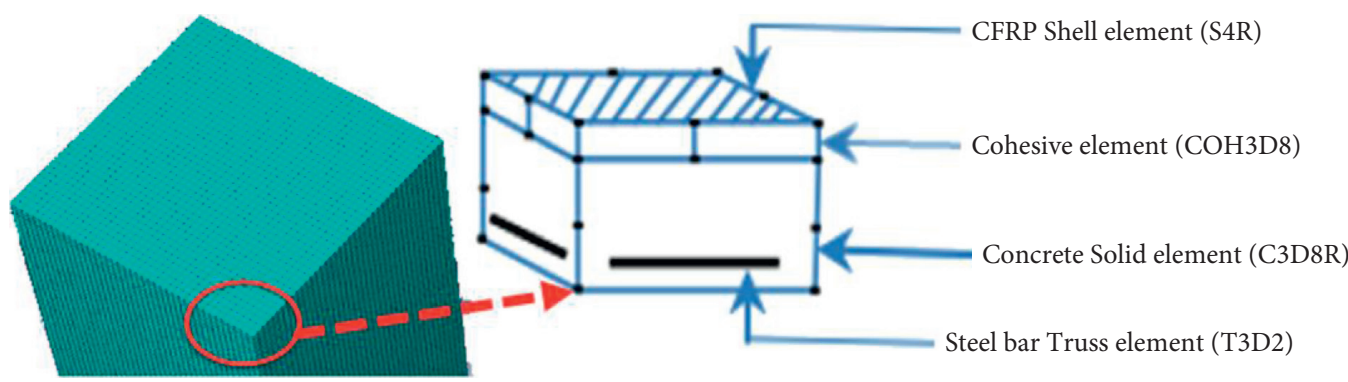

FiguRe 3: CFRP strengthened RC column model element types.

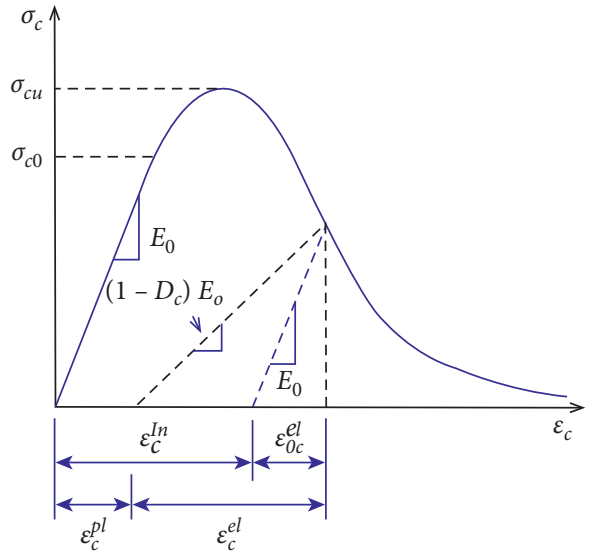

(a)

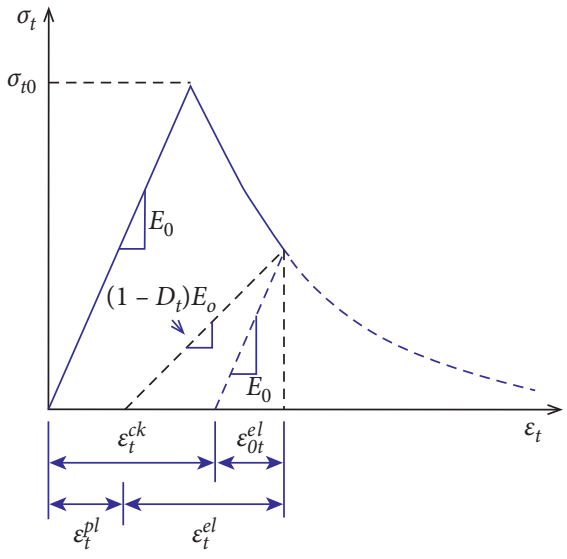

(b)

FIGURE 4: Concrete damage plasticity model: (a) compressive behavior; (b) tensile behavior [9].

According to Eurocode 2, which is determined using equation (5), the uniaxial compression stress-strain relation of concrete has been depicted in Figure 5(a) [10]: where $\sigma_{c}$ is the concrete compressive stress, $\eta=\varepsilon_{c} / \varepsilon_{c 1}$ with $\varepsilon_{c 1}=0.7 f_{c m}^{0.13}$ is the strain at peak stress, and $k=1.05 E_{c m}\left|\varepsilon_{c 1}\right| / f_{c m}$ is the plasticity number. Furthermore, $\mathrm{E}_{\mathrm{cm}}$ and $\mathrm{f}_{\mathrm{cm}}$ are the secant modulus of elasticity and the mean value compressive strength of concrete.

$$
\frac{\sigma_{c}}{f_{c m}}=\frac{k \eta-\eta^{2}}{1+(k-2) \eta},
$$

(2) Concrete Tensile Behavior. Once concrete material has been cracked, the postfailure tensile behavior can be modeled with tension stiffening, a phenomenon that defines the interaction of reinforcement with concrete and strain softening. In the CDP model, tension stiffening of concrete can be specified by either postfailure stress-strain relation or fracture energy cracking criterion. In this study, as shown in Figure 5(b), to describe the tensile behavior of cracked concrete section, the fracture energy concept (i.e., stress versus crack opening) was employed $[11,12]$. 


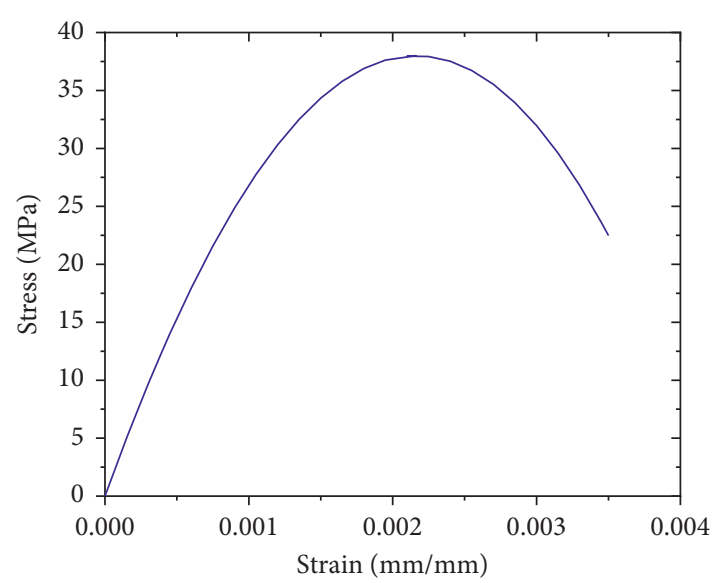

(a)

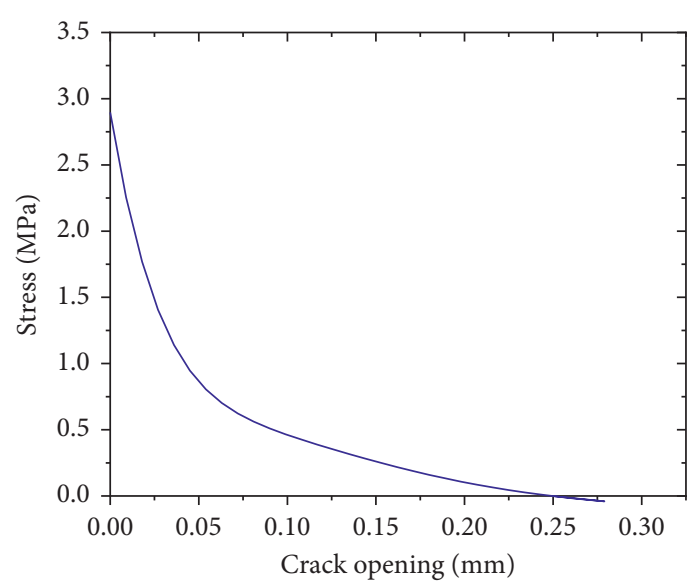

(b)

FIgURE 5: Concrete material response: (a) compressive stress-strain relation; (b) postfailure tensile behavior.

2.3.2. Steel Reinforcement Bar. The RC columns were reinforced with $20 \mathrm{~mm}$ deformed bars and $8 \mathrm{~mm}$ stirrups having yield strengths of $550 \mathrm{MPa}$ and $460 \mathrm{MPa}$, respectively. Since steel reinforcement is a homogeneous material, a single stress-strain relationship is sufficient to define the steel material properties needed in the nonlinear FE model. As recommended by Kachlakev et al. [13], the plastic part of steel behavior can be modeled as an elastic perfectly plastic material using a strain hardening ratio of 0.01 (see Figure 6).

2.3.3. CFRP. CFRP is a synthetic material consisting of two parts, namely, the fiber reinforcement that provides strength to the composite and the matrix as a binder of the fibers. When CFRP is subjected to impact load, it undergoes internal damages in the form of resin matrix cracking, fiber fracture, or interlaminar delamination. Thus, the damage model of CFRP material requires specifying three material responses: (a) undamaged (i.e., linearly elastic) response, (b) damage initiation criterion, and (c) damage evolution response (see Figure 7) [9]. While the elastic phase of the lamina was defined using modulus of elasticity, Poisson's ratio, and the shear modulus of elasticity in all directions, the damage initiation was modeled based on Hashin's damage model [14]. Finally, the damage evolution response of the fiber was adopted based on the fracture energy dissipated during the damage process.

Hashin's damage model considers four different damage initiation mechanisms: fiber rupture in tension, fiber buckling in compression, matrix cracking under transverse tension and shearing, and matrix crushing under transverse compression and shearing as described correspondingly from equation (6) to equation (9). Furthermore, the input values for Hashin's damage criterion are summarized in Table 1 .

Fiber tension $\left(\sigma_{11} \geq 0\right)$ :

$$
F_{f}^{t}=\left(\frac{\sigma_{11}}{X^{T}}\right)^{2}+\alpha\left(\frac{\tau_{12}}{S^{L}}\right)^{2}=1 ; 0 \leq \alpha \leq 1
$$

Fiber compression $\left(\sigma_{11} \geq 0\right)$ :

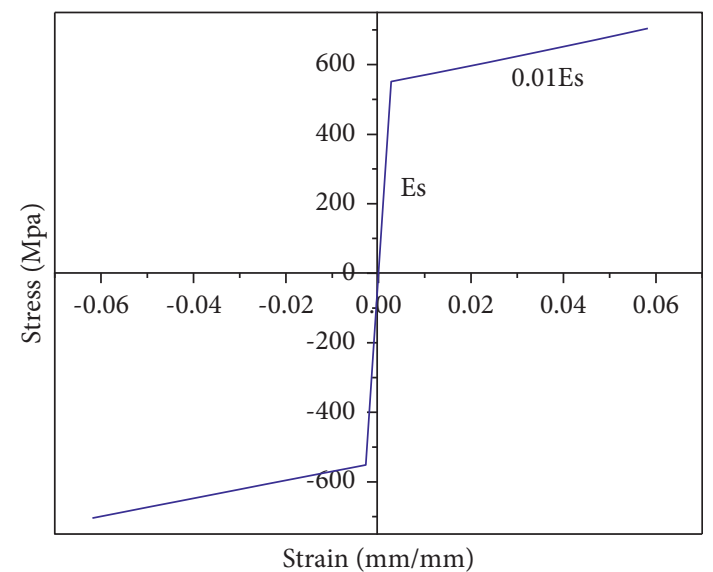

Figure 6: FE analysis steel bar material model.

$$
F_{f}^{c}=\left(\frac{\sigma_{11}}{X^{c}}\right)^{2}=1
$$

Matrix tension $\left.\left(\sigma_{22} \geq 0\right)\right)$ :

$$
F_{m}^{t}=\left(\frac{\sigma_{22}}{Y^{T}}\right)^{2}+\alpha\left(\frac{\tau_{12}}{S^{L}}\right)^{2}=1 .
$$

Matrix compression $\left(\sigma_{22} \geq 0\right)$ :

$$
F_{m}^{c}=\left(\frac{\sigma_{22}}{2 S^{T}}\right)^{2}+\left[\left(\frac{Y^{c}}{2 S^{T}}\right)^{2}-1\right] \frac{\sigma_{22}}{Y^{c}}+\left(\frac{\tau_{12}}{S^{L}}\right)^{2}=1,
$$

where $\sigma_{11}, \sigma_{22}$, and $\tau_{12}$ are components of the effective stress tensors, $X^{T} \& X^{c}$ denote longitudinal tensile and compressive strength, $Y^{T}, Y^{c}$ denote the transverse tensile and compression fiber strength, and $S^{T}, S^{c}$ denote longitudinal and transverse shear strength, respectively.

2.3.4. Cohesive Element. The interfacial region (adhesive joint) between the RC column and CFRP laminate was modeled using Sikadur 330 epoxy resin as a cohesive element. Based on the mechanical constitutive responses, modeling of 


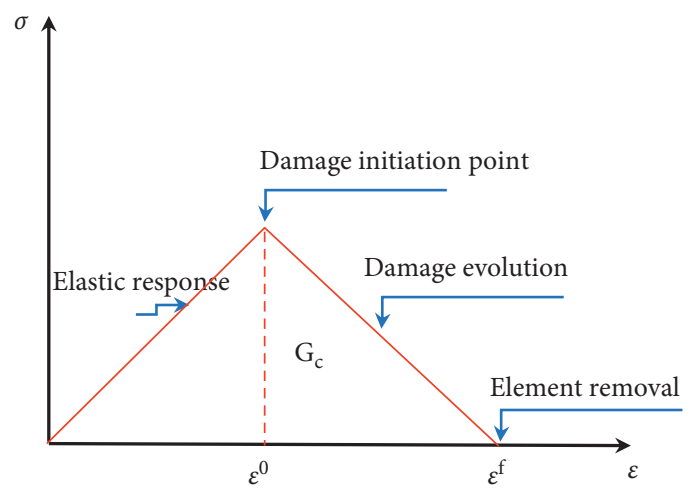

FIgURE 7: Damage response of CFRP material.

TABLE 1: Material properties of unidirectional fiber reinforced sheet [15].

\begin{tabular}{|c|c|c|c|c|c|c|c|c|c|c|}
\hline \multirow{2}{*}{ Parameters } & \multicolumn{10}{|c|}{ Elastic property } \\
\hline & \multicolumn{4}{|c|}{ E2 } & \multicolumn{2}{|c|}{$\nu 12$} & \multicolumn{3}{|c|}{ G13 } & G23 \\
\hline Unit & \multicolumn{3}{|c|}{$\mathrm{MPa}$} & & \multicolumn{2}{|c|}{-} & \multicolumn{4}{|c|}{$\mathrm{MPa}$} \\
\hline Value & 205,000 & & 25,000 & & & & $1 \times 10-6$ & & & 3,000 \\
\hline \multirow{2}{*}{ Parameters } & \multicolumn{6}{|c|}{ Damage initiation } & \multicolumn{4}{|c|}{ Damage evolution } \\
\hline & $\mathrm{XT}$ & $\mathrm{XC}$ & $\mathrm{YT}^{\circ}$ & $\mathrm{YC}$ & SL & ST & GT1C & $\mathrm{GC1C}$ & GT2C & $\mathrm{GC} 2 \mathrm{C}$ \\
\hline Unit & \multicolumn{6}{|c|}{$\mathrm{MPa}$} & \multicolumn{4}{|c|}{$\mathrm{N} / \mathrm{m}$} \\
\hline Value & 2,760 & 552 & $1 \times 10-6$ & $\begin{array}{c}1 \times 10- \\
6\end{array}$ & 50 & $1 \times 10-6$ & 91,600 & 79,900 & 1 & 1 \\
\hline
\end{tabular}

the cohesive element can be (a) continuum description of the material, (b) traction separation description of the interface, or (c) gaskets modeling [9]. In this study, because of very thin adhesive layer thickness (i.e., practically considered zero), the traction versus separation model was adopted. As shown in Figure 8, the triangular traction separation model in Abaquas assumes initially linear elastic behavior followed by the initiation and evolution of damage. The linear elastic behavior before the damage initiation is expressed in terms of an elastic constitutive matrix that relates the nominal stresses $\{\sigma\}$ to the nominal strains $\{\varepsilon\}$ across the cohesive element [9]. For uncoupled elastic behavior, the stress-strain relations can be described as

$$
\left\{\begin{array}{c}
\sigma_{n} \\
\sigma_{s} \\
\sigma_{t}
\end{array}\right\}=\left[\begin{array}{ccc}
E_{n n} & 0 & 0 \\
0 & E_{s s} & 0 \\
0 & 0 & E_{t t}
\end{array}\right]\left\{\begin{array}{c}
\varepsilon_{n} \\
\varepsilon_{s} \\
\varepsilon_{t}
\end{array}\right\}
$$

where $\varepsilon_{n}=\delta_{n} / T_{0}, \varepsilon_{s}=\delta_{s} / T_{0}, \varepsilon_{t}=\delta_{t} / T_{0}$ and $\delta_{n}, \delta_{s}, \delta_{t}$ are the nominal strains and separations corresponding to the normal and two local shear directions, respectively, and $T_{o}$ is the original thickness of the cohesive element.

Similar to CFRP composite, damage initiation of a cohesive element refers to a point that corresponds to the onset of degradation of stiffness material. As clearly expressed from Equation (11) to Equation (14), respectively, traction separation law in Abaqus adopts four different damage initiation failure criteria, namely, maximum nominal stress, maximum nominal strain, quadratic nominal stress, and quadratic nominal strain failure criteria. A value of one or higher of these conditions indicates that the initiation criterion has been met [9].

(1) Maximum nominal stress criterion (MAXS):

$$
\operatorname{MAX}\left\{\frac{\sigma_{n}}{N_{\max }}, \frac{\sigma_{s}}{S_{\max }}, \frac{\sigma_{t}}{T_{\max }}\right\}=1 .
$$

(2) Maximum nominal strain criterion (MAXE):

$$
\operatorname{MAX}\left\{\frac{\varepsilon_{n}}{\varepsilon_{n}^{\max }}, \frac{\varepsilon_{s}}{\varepsilon_{s}^{\max }}, \frac{\varepsilon_{t}}{\varepsilon_{t}^{\max }}\right\}=1 .
$$

(3) Quadratic nominal stress criterion (QUADS):

$$
\left(\frac{\sigma_{n}}{N_{\max }}\right)^{2}+\left(\frac{\sigma_{s}}{S_{\max }}\right)^{2}+\left(\frac{\sigma_{t}}{T_{\max }}\right)^{2}=1
$$

(4) Quadratic nominal strain criterion (QUADS):

$$
\left(\frac{\varepsilon_{n}}{\varepsilon_{n}^{\max }}\right)^{2}+\left(\frac{\varepsilon_{s}}{\varepsilon_{s}^{\max }}\right)^{2}+\left(\frac{\varepsilon_{t}}{\varepsilon_{t}^{\max }}\right)^{2}=1,
$$

where $\sigma_{n}, \sigma_{s}$, and $\sigma_{t}$ are nominal stresses, $N_{\text {max }}, S_{\text {max }}$, and $T_{\text {max }}$ denote the maximum stresses, $\varepsilon_{n}, \varepsilon_{s} \& \varepsilon_{t}$ denote the nominal strains, and $\varepsilon_{n}^{\max }, \varepsilon_{s}^{\max } \& \varepsilon_{t}^{\max }$ denote the maximum strains in pure normal mode, first shear direction, and second shear directions, respectively. Moreover, the mechanical properties of the adhesive element are listed in Table 2. 


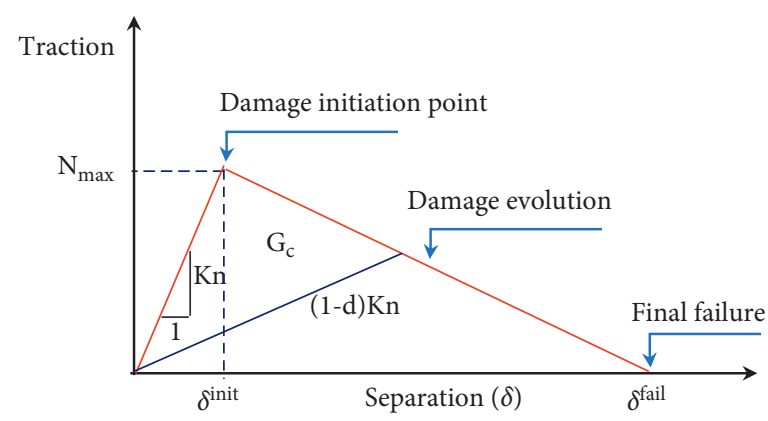

Figure 8: Traction separation model of cohesive element.

TABLe 2: Mechanical properties of adhesive material [15].

\begin{tabular}{|c|c|c|c|c|c|c|c|c|c|c|c|}
\hline \multirow{2}{*}{ Parameters } & \multicolumn{5}{|c|}{ Linear elasticity } & \multicolumn{3}{|c|}{ Damage initiation } & \multicolumn{3}{|c|}{ Damage evolution } \\
\hline & Density & $\mathrm{K}_{\mathrm{nn}}$ & $\mathrm{K}_{\mathrm{ss}}$ & $\mathrm{K}_{\mathrm{tt}}$ & $\mathrm{Ea}$ & $\sigma_{\mathrm{n}}$ & $\sigma_{\mathrm{t}}$ & $\sigma_{\mathrm{s}}$ & $G_{\mathrm{n}}$ & $G_{\mathrm{s}}$ & $G_{\mathrm{t}}$ \\
\hline Unit & $\mathrm{kg} / \mathrm{m}^{3}$ & & $\mathrm{~N} / \mathrm{m}$ & & \multicolumn{4}{|c|}{$\mathrm{MPa}$} & & $\mathrm{N} / \mathrm{m}$ & \\
\hline Value & 1300 & 23.6 & 23.6 & 4,820 & 31.28 & 31.28 & 31.28 & 1,000 & 1,250 & 1,250 & 1,250 \\
\hline
\end{tabular}

2.4. Strain Rate. As compared to the static load case, the mechanical properties of most material under dynamic load are quite different. While the static strain rate is found in the range of $10^{-6}$ to $10^{-5} \mathrm{~S}^{-1}$, the impact load is associated with strain rate in the range of $10^{\circ}$ to $10^{2} \mathrm{~S}^{-1}$ [16]. For $\mathrm{RC}$ structures subjected to impact load (i.e., high strain rate), the strength of concrete and steel materials is enhanced. During the numerical simulation, the strain rate can be accounted with the dynamic increase factor (DIF) [17]. The dynamic increase factor of a given material can be well defined as the ratio of dynamic strength to the strength at quasistatic strain rates.

As readily depicted in Figures 9(a) and 9(b), an increase of strain rate results in corresponding increases in the ultimate tensile stress and compressive stress of concrete material. Therefore, to forecast the reliable impact load responses of the concrete and steel reinforcement material models, the effect of strain rate sensitivity on the dynamic response of the structure can be defined by multiplying their static values by DIF [18]. In this study, the corresponding DIF for tensile and compressive strength of concrete material was defined using empirical formulas given in Equations (15) and (16), respectively [12, 17].

$$
D I F_{c t}=\frac{f_{t}}{f_{t s}}=\left\{\begin{array}{ll}
\left(\frac{\dot{\varepsilon}}{\dot{\varepsilon}_{t s}}\right)^{\delta}, & \text { for } \dot{\varepsilon} \leq 1 s^{-1} \\
\beta\left(\frac{\dot{\varepsilon}}{\dot{\varepsilon}_{t s}}\right)^{1 / 3}, & \text { for } \dot{\varepsilon}>1 s^{-1}
\end{array},\right.
$$

where $f_{t}$ is the dynamic tensile strength at a strain rate $\dot{\varepsilon}$ which is in the range of $10^{-6}$ to $160 \mathrm{~s}^{-1}$ and $f_{t s}$ is the static tensile strength at $\dot{\varepsilon}_{t s}, \log \beta=6 \delta-2, \delta=1 /\left(1+8 f_{c}^{\prime} / f_{c o}^{\prime}\right)$, in which $f_{c}^{\prime}$ is the static uniaxial compressive strength of concrete (in $\mathrm{MPa}$ ) and $f_{c 0}^{\prime}$ equals $10 \mathrm{MPa}$.

$$
D I F_{c c}=\frac{f_{c}}{f_{c s}}=\left\{\begin{array}{ll}
\left(\frac{\dot{\varepsilon}}{\dot{\varepsilon}_{c s}}\right)^{1.026 \alpha} & \text { for } \dot{\varepsilon} \leq \frac{30}{s} \\
\gamma(\dot{\varepsilon})^{1 / 3} & \text { for } \dot{\varepsilon}>\frac{30}{s}
\end{array},\right.
$$

where $f_{c}$ is dynamic compressive strength at a strain rate $\dot{\varepsilon}$, $f_{c s}$ is the static compressive strength at $\dot{\varepsilon}_{c s}$, $\log \gamma=6.156 \alpha-0.49, \alpha=1 /\left(5+3 \mathrm{f}_{\mathrm{cu}} / 4\right)$, and $\mathrm{f}_{\mathrm{cu}}(\mathrm{MPa})$ is the static cube strength of concrete.

As with concrete material, a high loading rate on reinforcement steel bars also increases the yield stress to values beyond the static case. Figure 10 shows the effect of strain rate on steel bar strength that reproduced using the following Equation (17):

$\alpha_{s}= \begin{cases}0.074-0.040 \frac{\mathrm{fy}}{414} ; & f_{y} \text { is steel yield stress }(\mathrm{MPa}), \\ 0.019-0.009 \frac{\mathrm{fy}}{414} ; & f_{y} \text { is ultimate stress }(\mathrm{MPa}) .\end{cases}$

Compared to steel reinforcement bar and concrete material, the strength increment of CFRP sheet due to the strain rate effect is insignificant [19]. Therefore, in the current study, the strain rate effect of CFRP is not considered.

\section{Results and Discussions}

3.1. Validation. To verify the numerical model, the results obtained from the FE analysis were compared with the experimental test. The impact force-time histories of FE analysis results along with experimental data are presented 


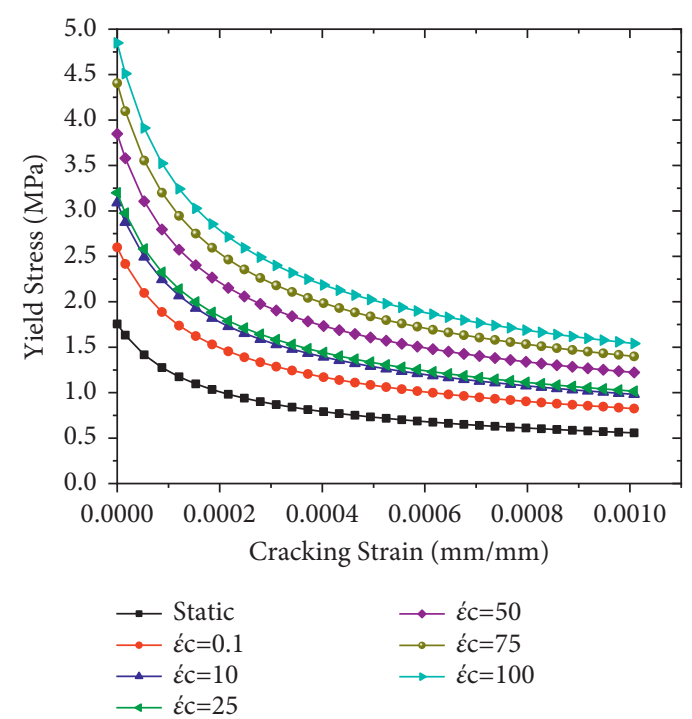

(a)

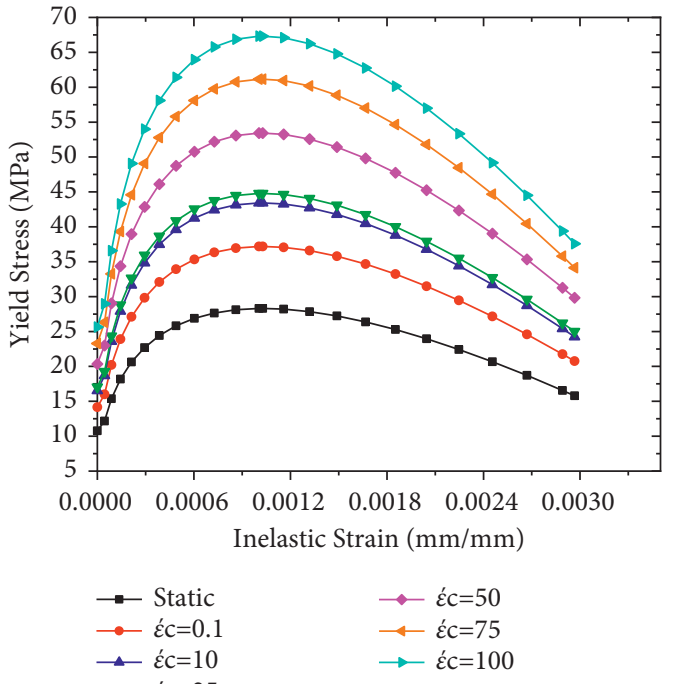

(b)

Figure 9: Strain rate effect on concrete material: (a) tensile strength; (b) compression strength.

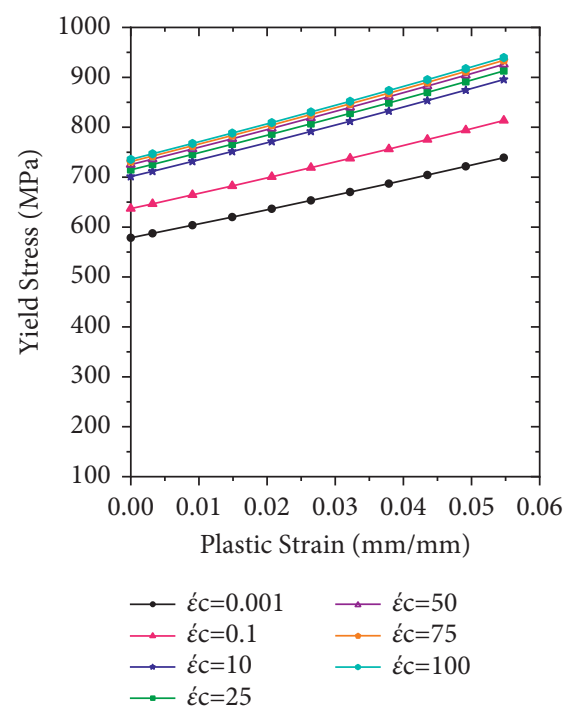

FIGURE 10: Strain rate effect on strength of steel reinforcement bar.

in Figure 11. As shown in Figures 11(a)-11(e), for all impact cases (i.e., $1^{\text {st }}$ to $5^{\text {th }}$ impact), the numerically obtained peak impact forces were consistent with the experimentally measured test results.

Figure 12 also validates the failure profiles of the CFRP confined FE analysis and the experimental test results of the $\mathrm{RC}$ column at the failure load stage. As shown, a good agreement is observed between the failure modes of nonlinear FE analysis and experimental results of the RC column. Overall, this indicates that the nonlinear FE analysis can provide a reasonable prediction of RC column impact behavior. Therefore, in this study, Abaqus/Explicit package was employed to investigate the behavior of the BRC column under repeated impact load.
3.2. Effect of CFRP Confinement on Impact Behavior of BRC Columns. Based on developed nonlinear FE simulations, this section presents the effect of CFRP confinement on the impact performance of BRC columns. For comparison purposes, except for the CFRP laminate, other material properties and geometric dimensions of the specimens are kept the same as in case of unstrengthened columns.

3.2.1. On the Impact Capacity. Figure 13 demonstrates the impact force-time histories of different BRC columns with variable initial velocities during the first impact. Since the impact energy is amplified, it is obvious that as the impact velocity increased, the peak impact force also increased. In 

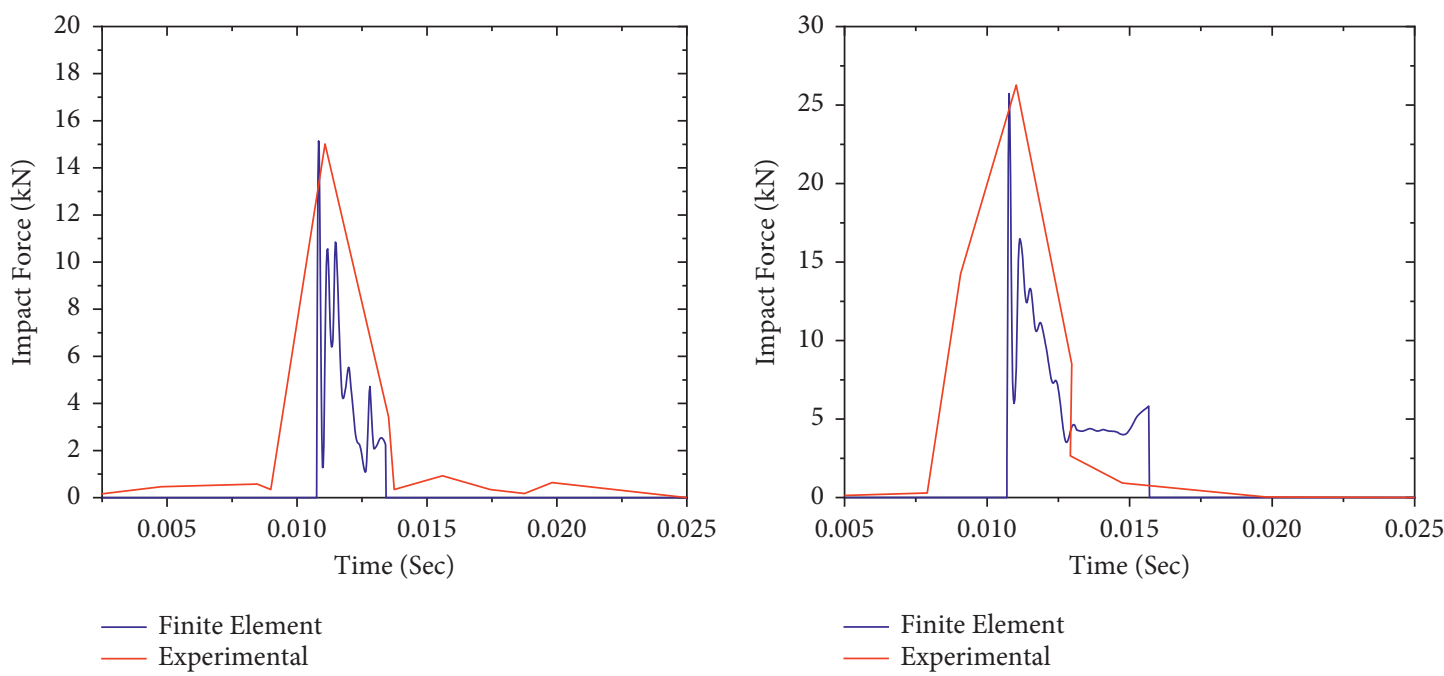

(a)

(b)
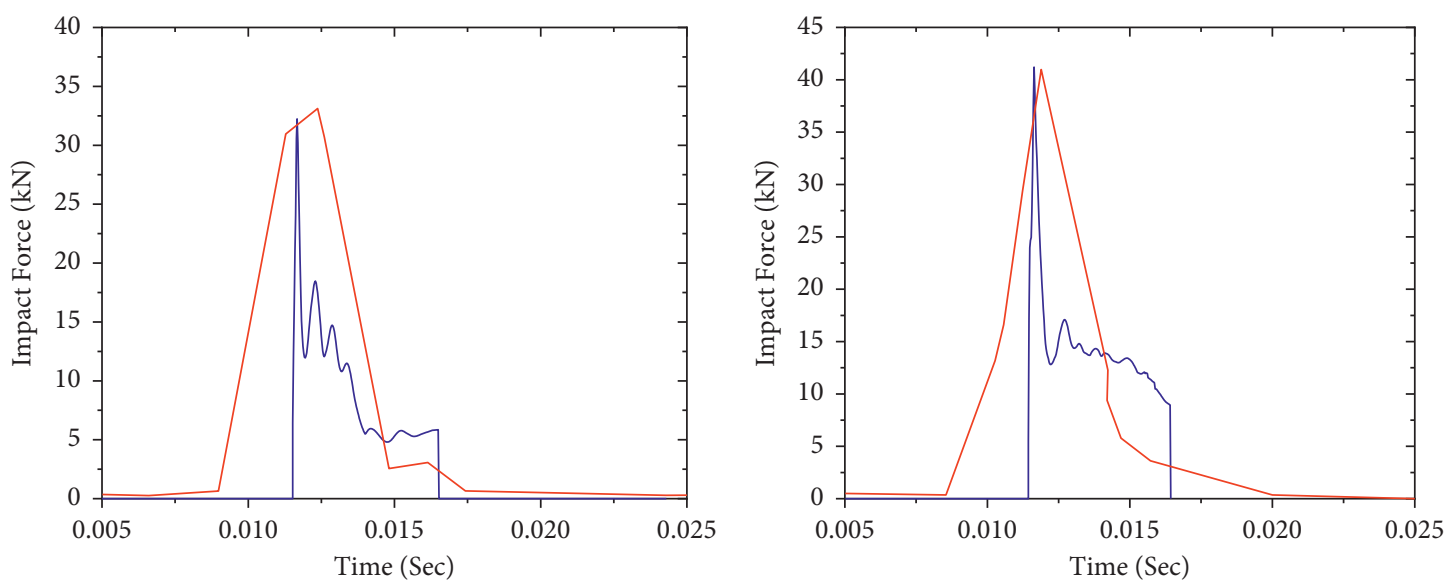

- Finite Elemen

— Finite Element

_ Experimental

(c)

(d)

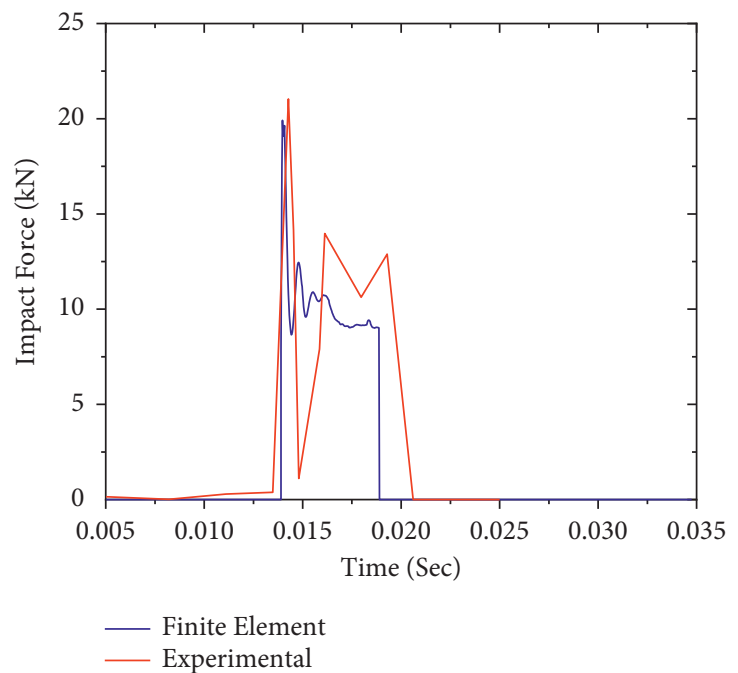

(e)

FIGURE 11: Impact force-time histories of numerical along with experimental test results: (a) $1^{\text {st }}$ impact; (b) $2^{\text {nd }}$ impact; (c) $3^{\text {rd }}$ impact; (d) $4^{\text {th }}$ impact; (e) $5^{\text {th }}$ impact. 


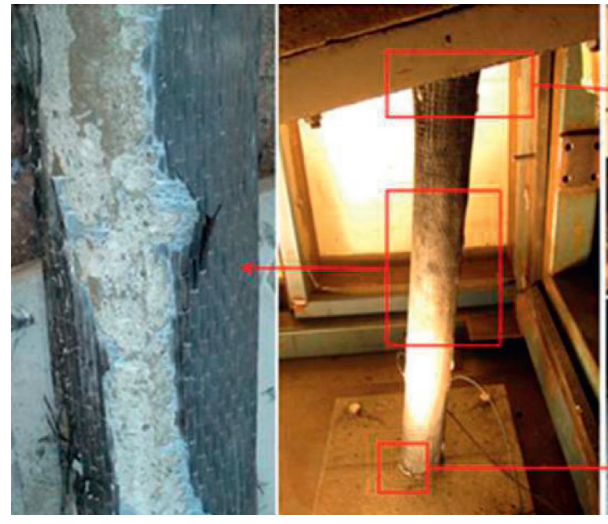

(a)

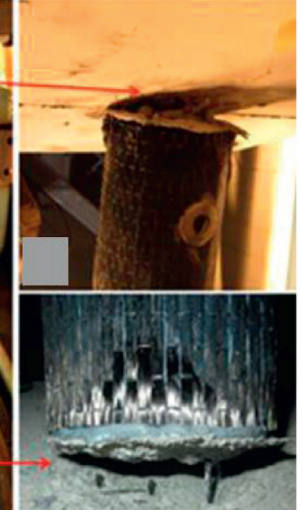

Figure 12: Comparison of damage modes at failure. (a) Experiment [3]. (b) Finite element.
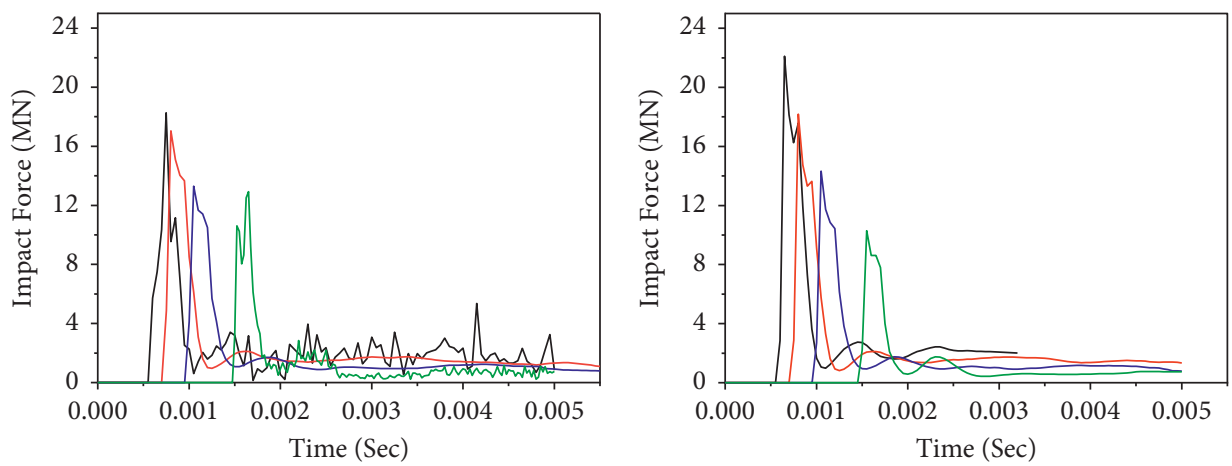

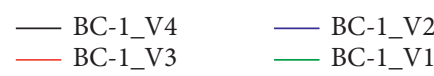

(a)

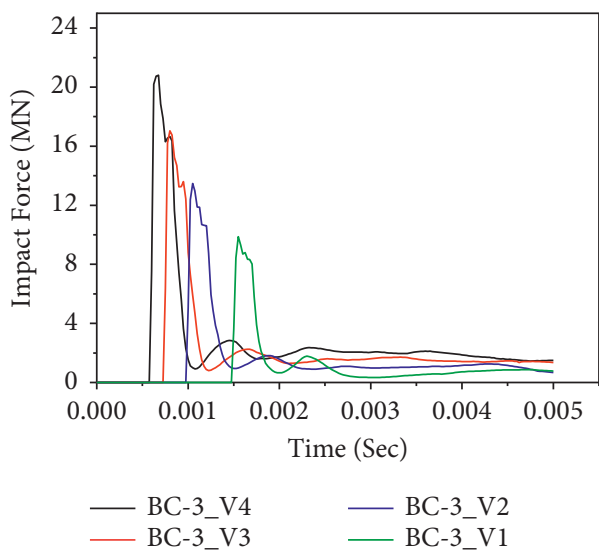

(c)

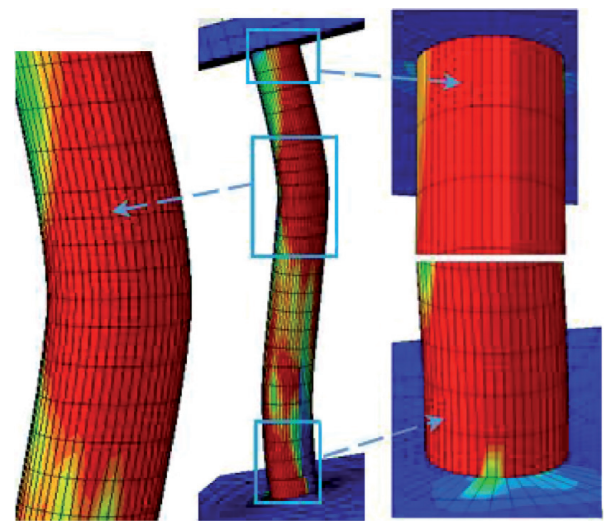

(b)

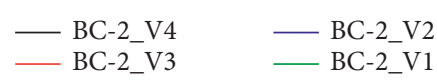

(b)

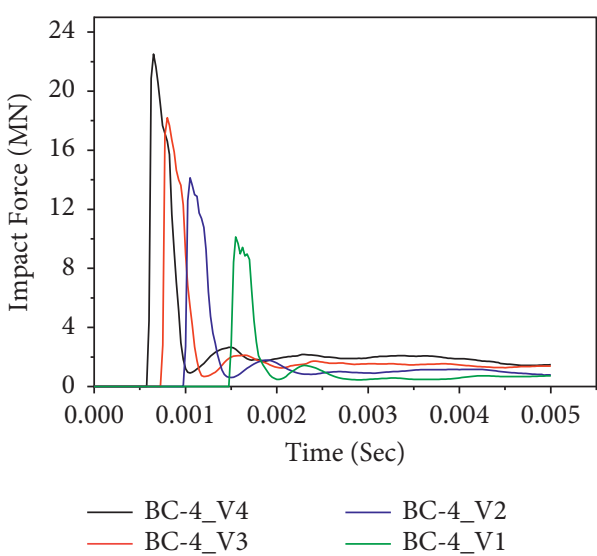

(d)

FIGURE 13: First impact force-time histories of unstrengthened BRC columns: (a) BC-1; (b) BC-2; (c) BC-3; (d) BC-4.

addition, as shown in Figure 13(b)), good impact capacity was observed in the case of two-bundle bars (BC-2) compared to other column specimens.

Figure 14 shows the impact force versus time of CFRP confined BRC columns. Compared to the impact capacities of as-built columns, the nonlinear FE analysis result revealed that the lateral confinement of CFRP improved the impact capacities of BRC columns. For example, at impact velocity of $15 \mathrm{~m} / \mathrm{s}$, the corresponding impact force improvements due to CFRP confinement are 33.76\%, $36.39 \%, 39.86 \%$, and $34.37 \%$ for BC-1, BC-2, BC-3, and BC-4 specimens, respectively. Moreover, the effect of CFRP confinement on the impact behavior of the BRC column is depicted in Figure 15. 

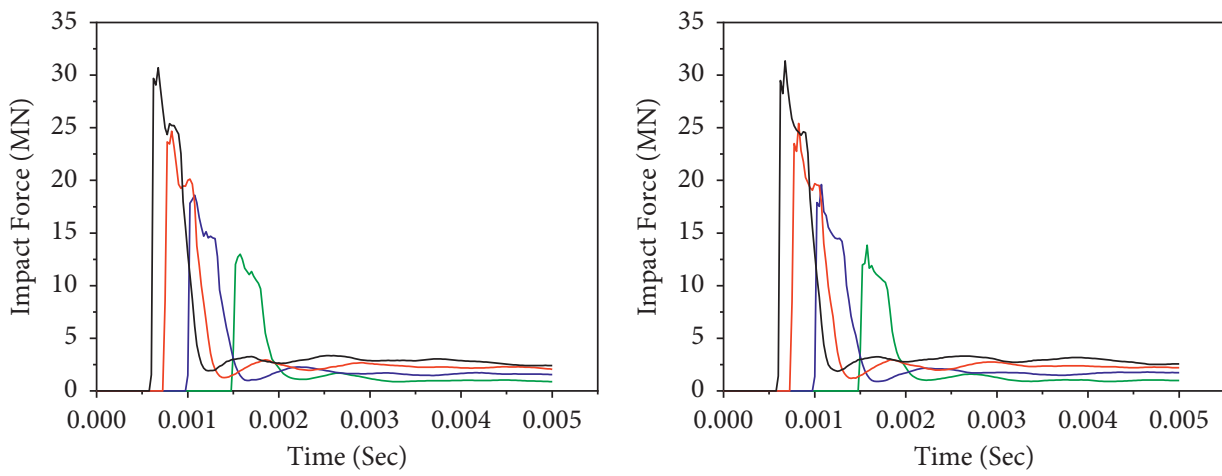

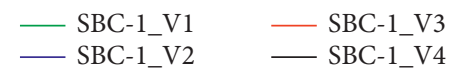

(a)

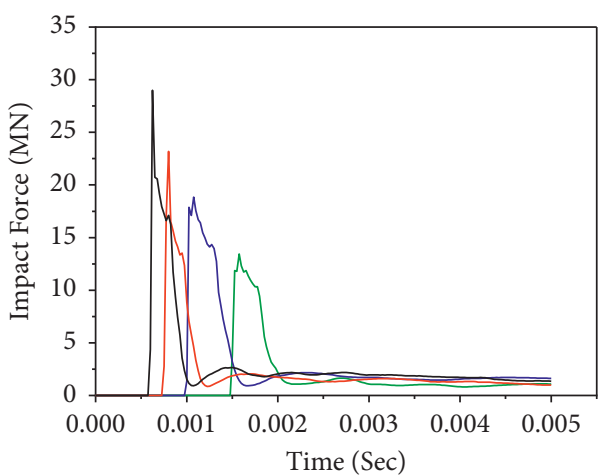

$\begin{array}{ll}\text { SBC-3_V1 } & \text { SBC-3_V3 } \\ \text { SBC-3_V2 } & \text { SBC-3_V4 }\end{array}$

(c)

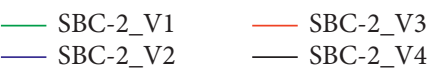

(b)

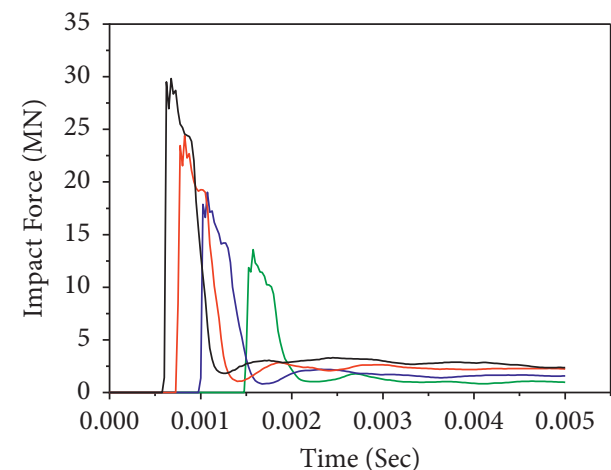

\begin{tabular}{ll} 
SBC-4_V1 & SBC-4_V3 \\
\hline SBC-4 V2 & SBC-4 V4
\end{tabular}

(d)

Figure 14: First impact force-time histories of CFRP confined BRC columns: (a) BC-1; (b) BC-2; (c) BC-3; (d) BC-4.

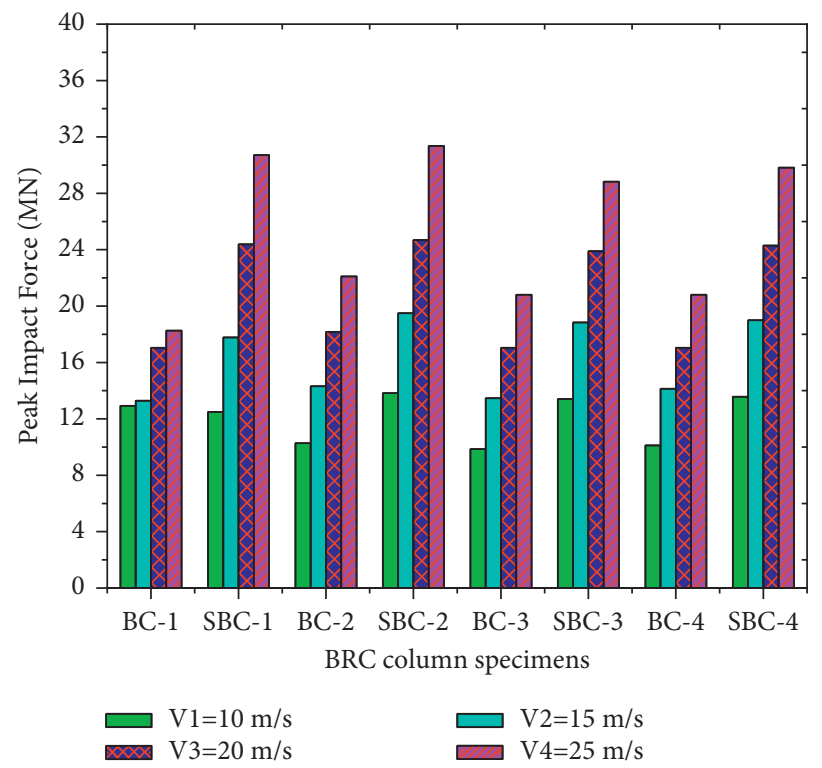

FIgURe 15: Peak impact force comparisons of BRC columns with and without CFRP. 

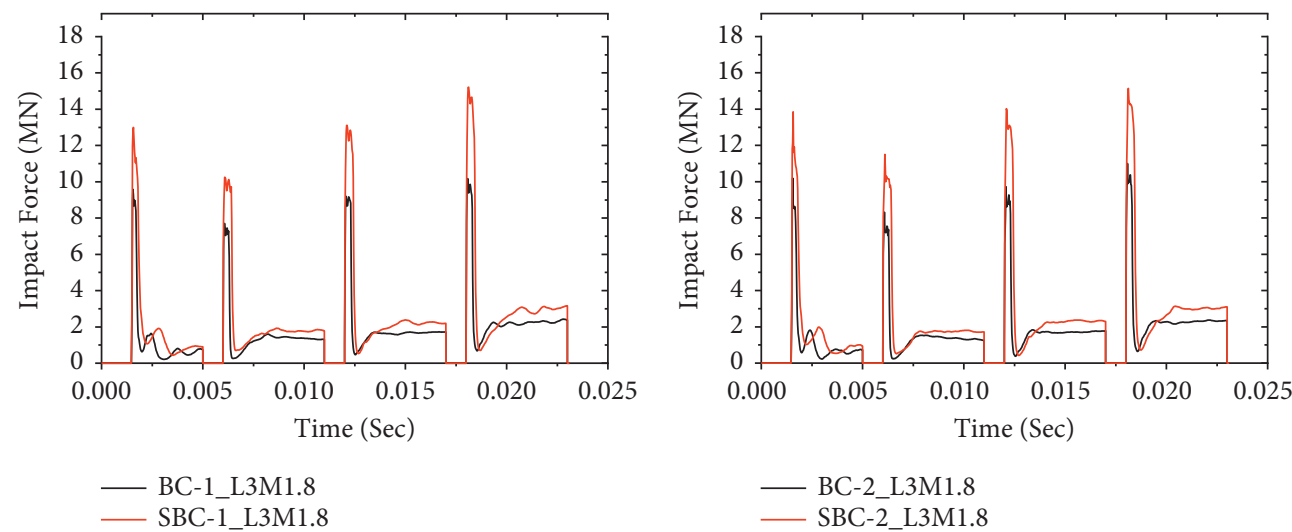

(a)
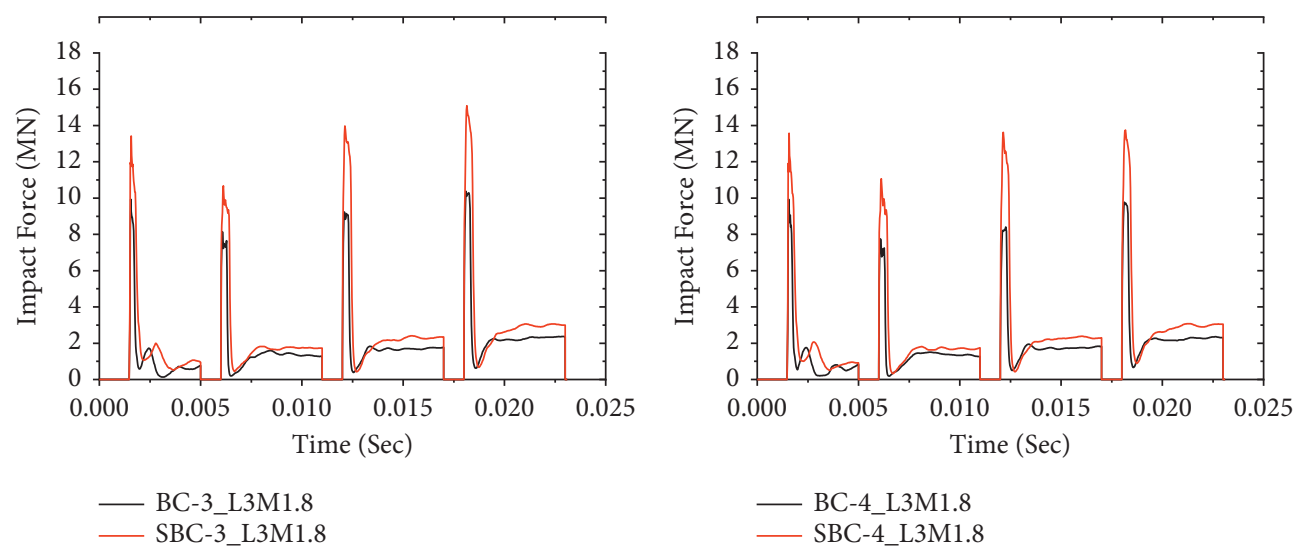

(c)

(d)

FIGURE 16: Effect of CFRP wrap on repeated impact capacity of BRC columns: (a) BC-1; (b) BC-2; (c) BC-3; (d) BC-4.

Figure 16 also reveals the impact force-time histories comparisons of BRC columns with and without CFRP wrap under repeated lateral impact. As shown in the figures, it is found that, at the same impact velocity, the maximum impact force of unstrengthen columns is lower than the CFRP strengthened BRC columns. This is because the CFRP confinement increases the column stiffness, and hence it improves the impact load resisting capacity of BRC columns. Compared to the first and second impact conditions, the peak impact force improvement due to CFRP wrapping is high on the $3^{\text {rd }}$ and $4^{\text {th }}$ impact.

3.2.2. On Damage Mode. RC structural members subject to impact load may damage either local failure at the impact zone or overall failure of the member. Local damage tends to be a common issue concerning $\mathrm{RC}$ plates while overall failure is associated with RC beams and columns subjected to impact load. As the single impacted unstrengthened BRC columns failed with the local shear failure, the repetitively impacted specimens were damaged by global failure [8].

In this study, as shown in Figure 17, when the impactor hit the BRC column at first impact with an initial velocity of $10 \mathrm{~m} / \mathrm{s}$, trivial cracks were originated at the tension face of the RC column. When the impact energy increased on the subsequent impacts, the tensile stress exceeds the tensile strength of concrete. At this stage, while the steel reinforcement carries the tensile stress of the unstrengthened cracked column, both steel reinforcement and CFRP laminate resist the cracked section of the CFRP confined BRC column. Therefore, compared to the CFRP wrapped specimens, the FE analysis result showed that for the same impact velocity the unstrengthened columns were damaged severely due to compression crashing and tensile cracking of concrete near the impact zone. The severe damage profiles at the third and fourth impacts of unstrengthened BRC columns were to some extent limited with CFRP confinement (refer to Figure 17(b)). This indicates that CFRP improved the impact-resisting capacity of RC columns by increasing the column stuffiness.

As stated previously, Hashin damage initiation of the laminate may fail due to fiber compression buckling, fiber tension fracture, matrix tensile cracking, and/or matrix compressive crushing. Figure 18 demonstrates the damage initiation profiles of the CFRP sheet from the first impact to the fourth impact. As it can be seen, the damage modes were described by using compressive buckling and tensile ruptures of fiber and matrix materials separately. The matrix material was severely damaged while the fiber showed only minor and gradual compressive failures. Compression fiber damage initiation criterion (maximum allowable value of one) of the CFRP sheet was reached after the third impact 

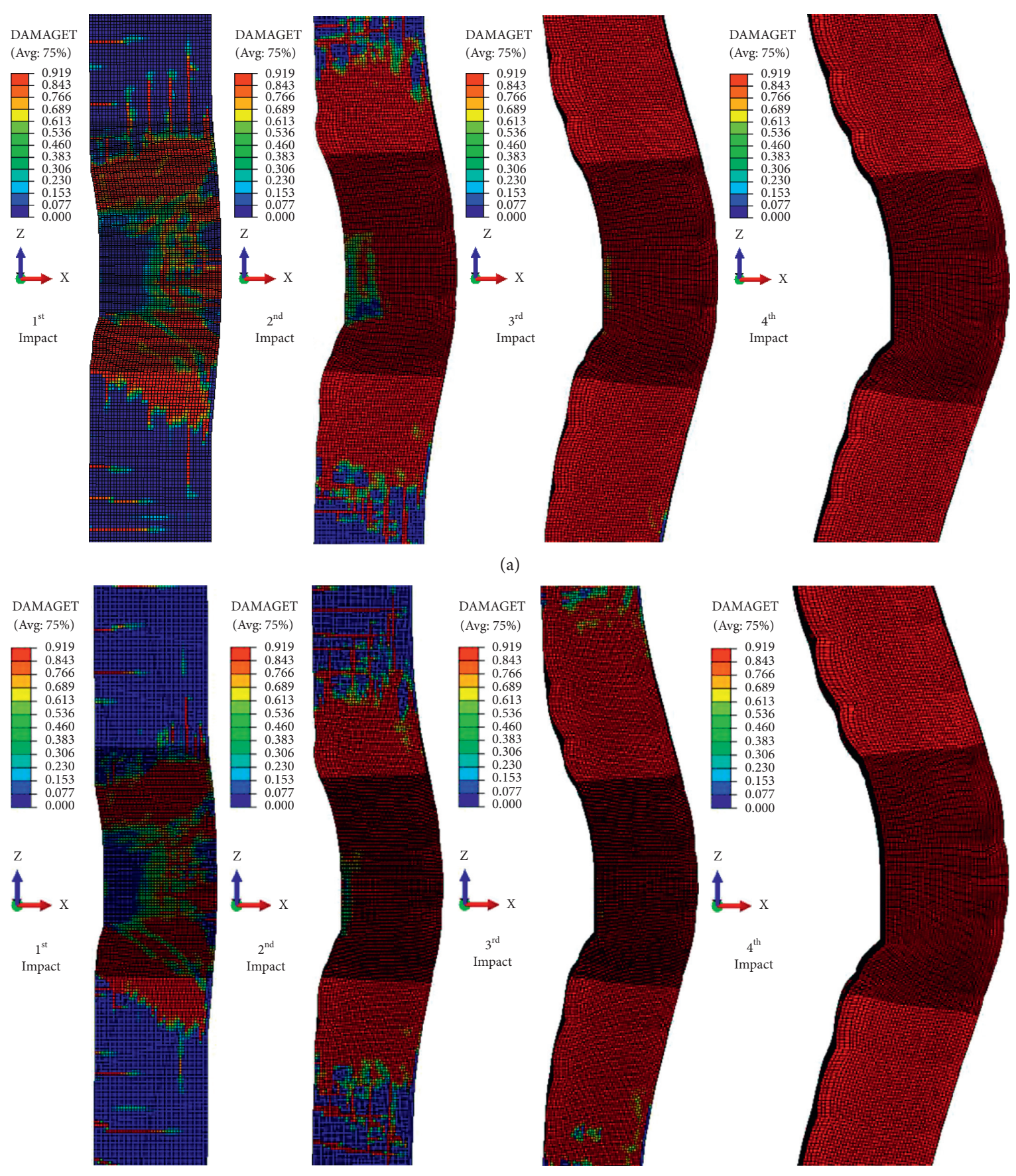

(b)

FIGURE 17: Concrete tensile damage subjected to repeated impact: (a) without CFRP confinement and (b) with CFRP confinement.

(refer to Figure 18(b)). However, as shown in Figure 18(a)), the tensile fiber failure does not reach damage initiation. This is because CFRP has high strength in tension. On the other hand, as shown in Figures 18(c) and 18(d), the continuous matrix was highly damaged in both tension cracking and compression crashing from the first impact.

3.3. Eccentric Axial Load. To understand the effect of eccentric axial load on impact performance BRC column, axial loads were employed by allowing some eccentricities from the center of the column cross section. Four different types of eccentricities, namely, positive $x$-axis (i.e., $\mathrm{ex}^{+}$), positive $x$-axis and positive $y$-axis $\left(\mathrm{ex}^{+} \mathrm{ey}^{+}\right)$, negative $x$-axis $\left(\mathrm{ex}^{-}\right)$, and negative $x$-axis with the negative $y$-axis (ex-ey ${ }^{-}$) are considered (refer to Figure 2(a)). In all cases, the axial load was shifted by $100 \mathrm{~mm}$ from the center of the RC column cross section.

The computed impact force histories of different BRC column models with variable axial load eccentricities are 

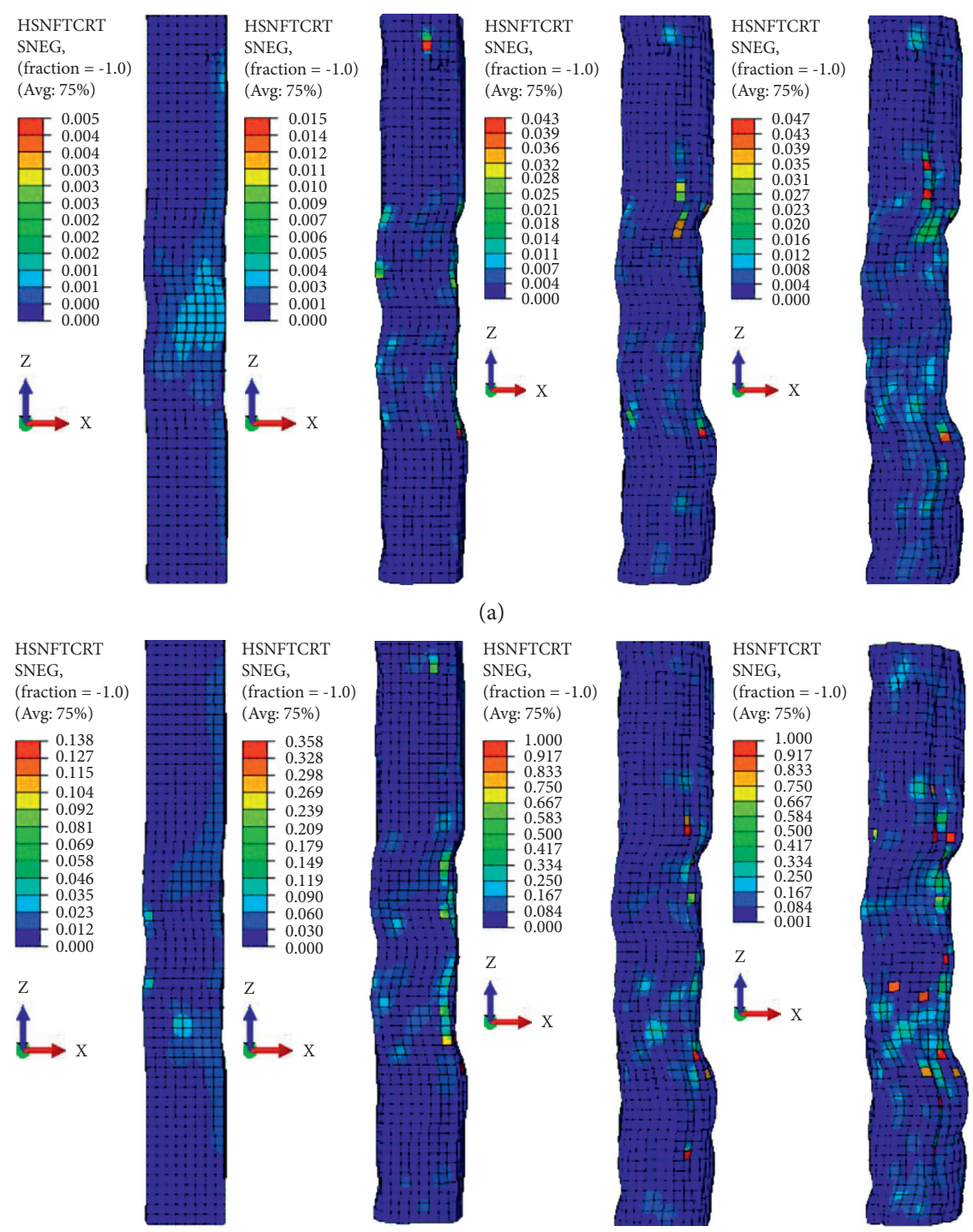

(b)
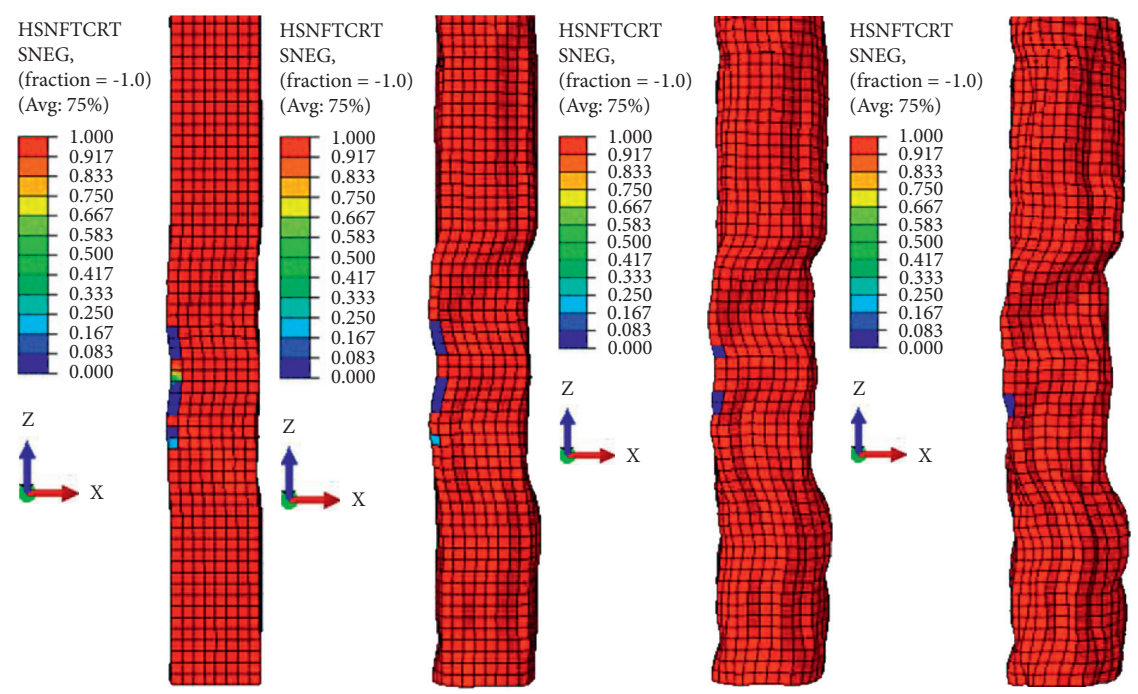

(c)

Figure 18: Continued. 

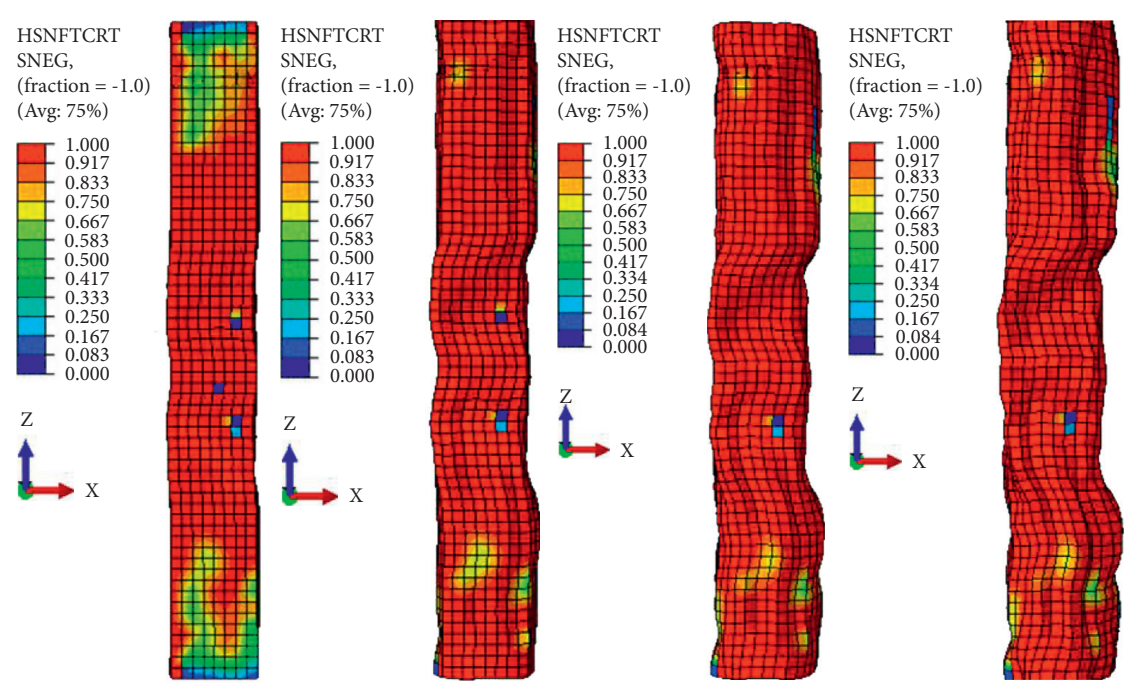

(d)

FIGURE 18: Hashin's damage criteria of CFRP: (a) fiber tensile rupture, (b) fiber compressive buckling, (c) matrix tensile cracking, and (d) matrix compressive crushing.

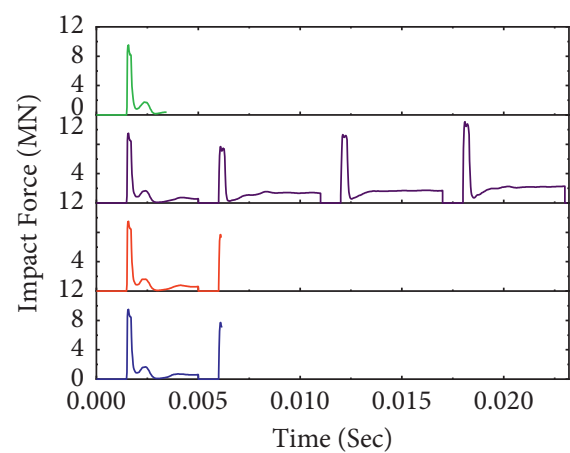

— BC-1_L3ex-ey- — BC-1_L3ex+ey+ - BC-1_L3ex- $\quad$ BC-1_L3ex+

(a)
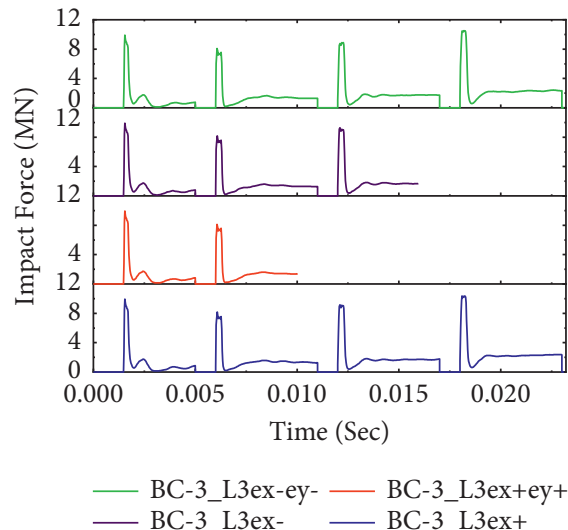

(c)

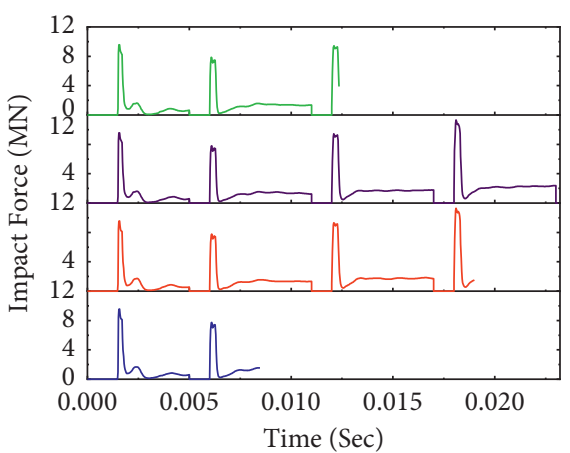

BC-2_L3ex-ey- - BC-2_L3ex+ey+ - BC-2_L3ex- - BC-2_L3ex+

(b)

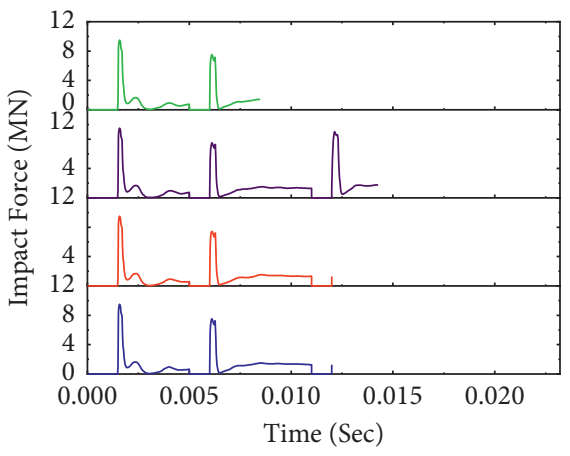

BC-4_L3ex-ey- - BC-4_L $23 e x+e y+$
BC-4_L3ex- - BC-4_L3ex+

(d)

FIgURE 19: Effect of eccentric axial load on impact capacity of BRC columns: (a) normal, (b) two-bundle, (c) three-bundle, and (d) four-bundle reinforcement distribution. 

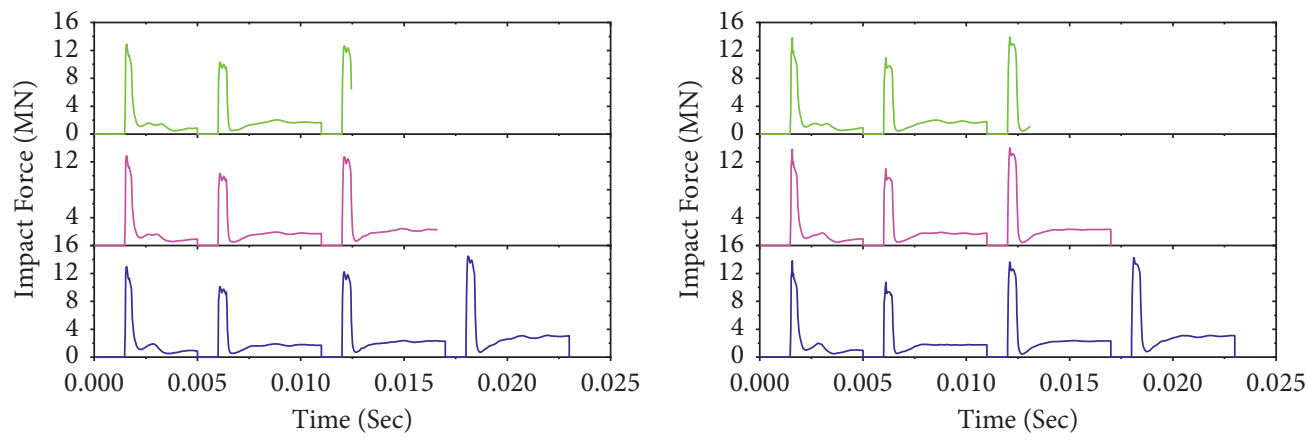

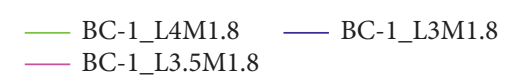

(a)

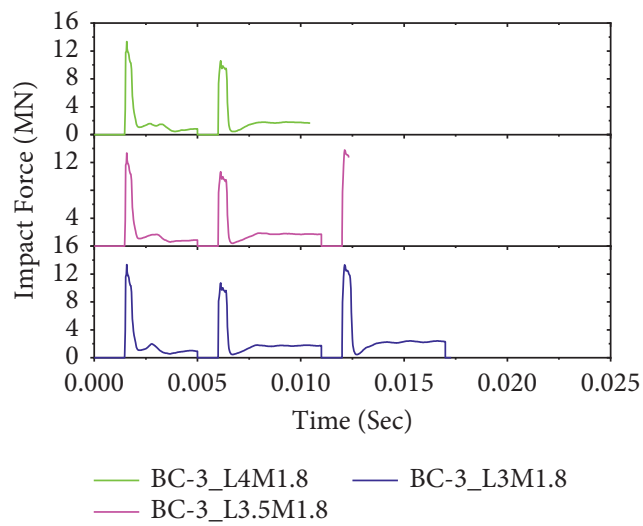

(c)

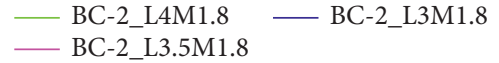

(b)

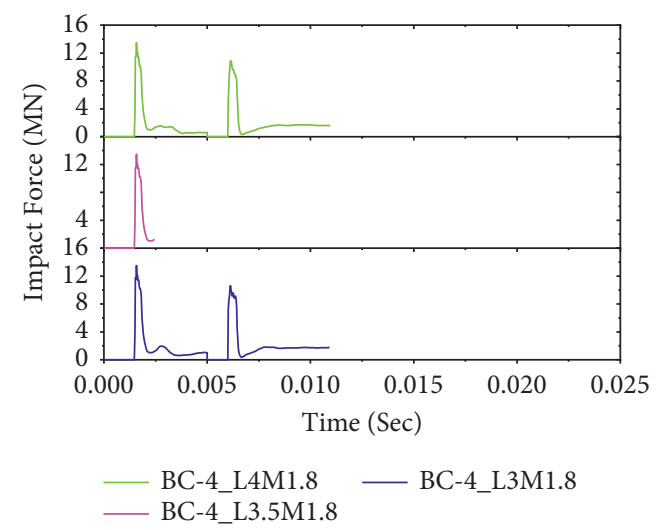

(d)

FIGURE 20: Effect of column height on impact capacity of BRC columns: (a) normal, (b) two-bundle, (c) three-bundle, and (d) four-bundle reinforcement distribution.

portrayed in Figure 19. As seen, it was found that except for three-bundle reinforcement distribution all other eccentrically loaded BRC column specimens (i.e., normal, two bundles, and four bundles) show good impact capacity in case of negatively $x$-axis $\left(\mathrm{ex}^{-}\right)$eccentric axial load. This is because the negatively $x$-axis eccentric axial load produces a bending moment that deflects the impacted column towards the impacted column face direction. Since concrete is good in compression, this moment improved the transverse impact capacity by increasing the column stiffness. On the other hand, in the case of three-bundle RC columns, good impact resistance was observed when the axial load was positioned at eccentricities of $\mathrm{ex}^{+}$and $\mathrm{ex}^{-} \mathrm{ey}$. This indicates that the corner bundle reinforcement of the three-bundle system is resistant for both $x$-axis and $y$-axis eccentric axial loads.

However, compared to pure axially loaded BRC columns, it was found that the impact capacities of BRC columns with eccentric axial load were significantly reduced [8]. This is because the additional bending moment generated from eccentric axial load reduces the column's impact capacity. Furthermore, compared to the other bundle bar distributions, two bundles showed good impact capacity; refer to Figure 19(b).

3.4. Effect of Column Height. The effect of column height on the impact performance of as-built BRC columns is shown in Figure 20. The numerical result revealed that the column height has no remarkable effect on the peak impact forces of BRC columns. But, as the height of the column increased from $3 \mathrm{~m}$ to $4 \mathrm{~m}$, the impacted BRC column specimens failed with the least repeated blows before reaching at the end of the fourth impact. This is because as the height of the column increased its stiffness was reduced and played additional moment (i.e., becoming slender and liable to buckle) and consequently lowered the impact capacity of the columns. On the other hand, compared to other bundle reinforcement distributions, two-bundle systems showed good impact resistance (see Figure 20(b)).

Figure 21 also illustrates the effect of column height on repeated impact behaviors of CFRP confined BRC columns without changing other parameters. Except for normal 


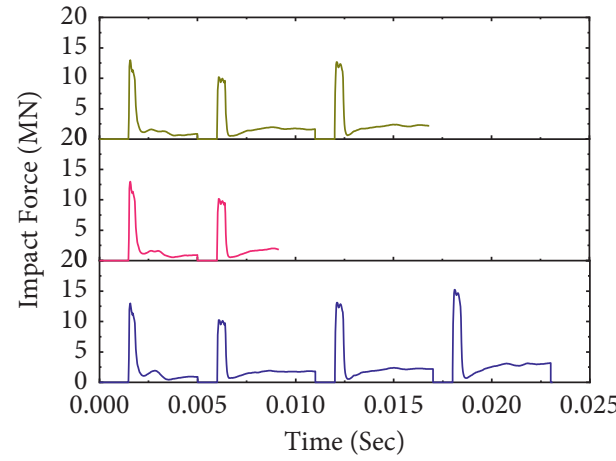

— SBC-1_L4M1.8

(a)

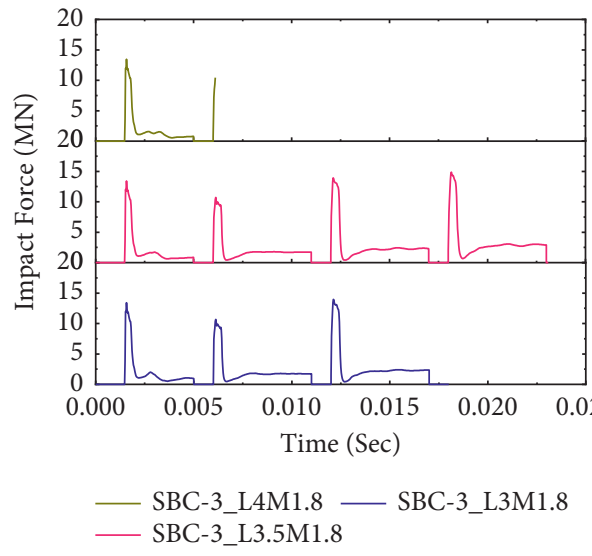

(c)

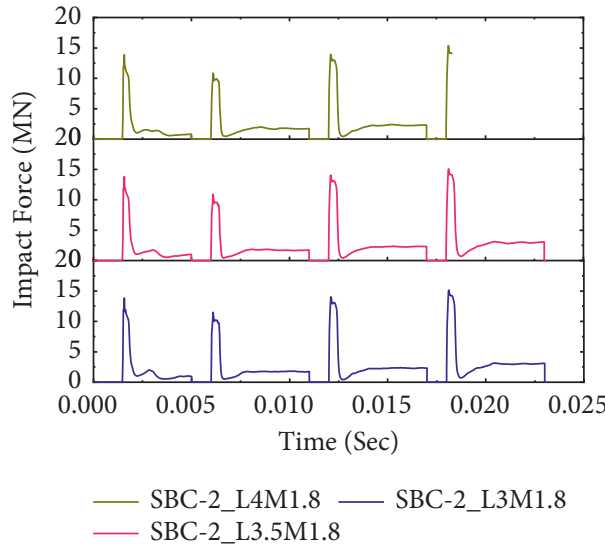

(b)

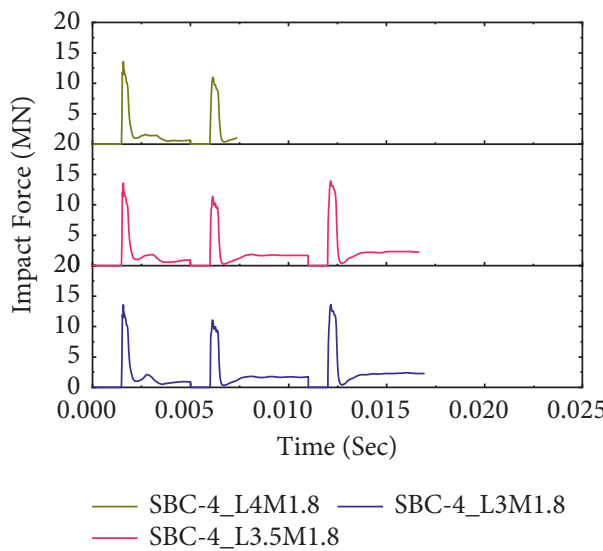

(d)

FIGURE 21: Influence of column height on impact capacity of CFRP confined BRC columns: (a) normal, (b) two-bundle, (c) three-bundle, and (d) four-bundle reinforcement distribution.

reinforced concrete column specimens (see Figure 21(a)), compared to unstrengthened columns, CFRP confinement improved the impact capacity of bundle reinforced columns. Overall, while impact performance was reduced with increasing column height, CFRP confinement improved the repeated impact capacity of bundled RC columns.

\section{Conclusion}

This study is aimed at numerical investigation of CFRP confined bundle reinforced concrete columns subjected to the repeated impact load using the Abaqus/Explicit package. Once the numerical model is verified with previous experimental tests, parametric studies were carried out to understand the effect of different variables on the impact behavior of BRC columns. Based on the FE analysis results presented in this paper, the following conclusions were drawn:

(1) During validation, it was found that the repeated impact FE analysis results showed good agreement with previous experimental measured data of the same member. This indicates that nonlinear FE analysis can provide a reasonable prediction of RC column impact behavior.

(2) By strengthening with CFRP sheet, the impact capacity of BRC column is significantly improved compared to the as-built column specimens. Additionally, the carbon fibers showed only minor and gradual compressive damages, while the matrix material is severely failed to start from the first impact. From this, it can be concluded that the high strength of the CFRP sheet is associated with discontinuous fibers.

(3) Based on the FE analysis results, compared to the pure axial load eccentrically loaded BRC column specimens showed lower repeated impact capacity. On the other hand, except for three-bundle bars, all other eccentrically loaded BRC column specimens (i.e., normal, two bundles, and four bundles) showed good impact capacity in case of negatively $x$-axis $\left(\mathrm{ex}^{-}\right)$eccentric axial load.

(4) The numerical result also revealed that column height has no remarkable effect on the peak impact forces BRC columns. However, as the height of the column increased, the impacted BRC column 
specimens failed with the least repeated blows before reaching the end of the fourth impact.

(5) Under the same impact energy, two-bundle RC columns showed good impact resistance capacity over the normal (i.e., without bundle), three-, and four-bundle reinforced concrete columns.

\section{Abbreviations}

\begin{tabular}{|c|c|}
\hline BRC: & Bundle reinforced concrete \\
\hline CFRP: & arbon fiber reinforced polymer \\
\hline DP: & Concrete damage plasticity \\
\hline IF: & Dynamic increase factor \\
\hline FE: & Finite element \\
\hline RC:Reinforced & Reinforced concrete: $\sigma_{11}, \sigma_{22}$, and \\
\hline ancrete. and & $\begin{array}{l}\tau_{12} \text { : Normal and shear fiber effective } \\
\text { stress }(\mathrm{MPa})\end{array}$ \\
\hline$X^{T} \& X^{c}:$ & $\begin{array}{l}\text { Longitudinal tensile and compressive } \\
\text { fiber strength }(\mathrm{MPa})\end{array}$ \\
\hline$Y^{T}, Y^{c}:$ & $\begin{array}{l}\text { Transverse tensile and compression } \\
\text { strength }(\mathrm{MPa})\end{array}$ \\
\hline$S^{T}, S^{c}:$ & $\begin{array}{l}\text { Longitudinal and transverse shear } \\
\text { strength }(\mathrm{MPa})\end{array}$ \\
\hline Gn, Gs, and Gt: & $\begin{array}{l}\text { Normal, first shear, and second shear } \\
\text { direction fracture energies }(\mathrm{N} / \mathrm{m})\end{array}$ \\
\hline Knn, Kss, and Ktt: & $\begin{array}{l}\text { Normal, first shear, and second shear } \\
\text { direction stiffness values }(\mathrm{N} / \mathrm{m} 3)\end{array}$ \\
\hline$\sigma_{n}, \sigma_{s}, \sigma_{t}:$ & $\begin{array}{l}\text { Normal, first shear, and second shear } \\
\text { direction nominal stresses }(\mathrm{MPa})\end{array}$ \\
\hline$\delta_{n}, \delta_{s}, \delta_{t}:$ & $\begin{array}{l}\text { Normal, first shear, and second shear } \\
\text { direction separations }(\mathrm{mm})\end{array}$ \\
\hline$\varepsilon_{n}, \varepsilon_{s} \& \varepsilon_{t}$ & $\begin{array}{l}\text { Normal, first shear, and second shear } \\
\text { direction nominal strains }(\mathrm{mm} / \mathrm{mm})\end{array}$ \\
\hline$\varepsilon_{t}, \varepsilon_{o t}^{e l}, \varepsilon_{t, d}^{e l}, \widetilde{\varepsilon}_{t}^{p l}:$ & $\begin{array}{l}\text { Total, elastic, damaged elastic, and } \\
\text { plastic concrete tensile strains }(\mathrm{mm} / \\
\mathrm{mm})\end{array}$ \\
\hline$\sigma_{c}, \sigma_{t}:$ & $\begin{array}{l}\text { Compressive and tensile concrete } \\
\text { stresses }(\mathrm{MPa})\end{array}$ \\
\hline & $\begin{array}{l}\text { Inelastic strain and cracking strain } \\
(\mathrm{mm} / \mathrm{mm}) .\end{array}$ \\
\hline
\end{tabular}

\section{Data Availability}

Additional data used to support the findings of this study are available from the author upon request, who can be contacted at aabay3013@gmail.com.

\section{Disclosure}

This research was made as partial fulfillment of the requirements for the award of Master of Science in structural engineering.

\section{Conflicts of Interest}

The author declares that there are no known conflicts of interest.

\section{Authors' Contributions}

The author is responsible for the content and writing of this article.

\section{Acknowledgments}

The author would like to acknowledge Addis Ababa Science and Technology University (AASTU) Mining Engineering Department Head for providing support to perform the FE simulation of the study.

\section{References}

[1] T. Tang and H. Saadatmanesh, "Behavior of concrete beams strengthened with fiber-reinforced polymer laminates under impact loading," Journal of Composites for Construction, vol. 7, no. 3, pp. 209-218, 2003.

[2] P. Isaac, A. Darby, T. Ibell, M. Evernden, and P. Silva, "Response of FRP wrapped RC columns to impact loads," in Advanced Composites in Construction 2011, pp. 252-263, ACIC 2011-Proceedings of the 5th International Conference, 2011.

[3] Y. Sha and H. Hong, "Laboratory tests and numerical simulations of CFRP strengthened RC pier subjected to barge impact load," International Journal of Structural Stability and Dynamics, vol. 15, p. 33, 2014.

[4] T. Liu and Y. Xiao, "Impact behavior of CFRP-stripwrapped," RC beams without stirrups, vol. 21, no. 5, Article ID 04017035, 2017.

[5] H. Dabbagh and \% Arina, "Nonlinear finite element modeling of different cross-sectional shapes of slender RC columns," Confined with CFRP Wraps, vol. 6, no. 2, pp. 58-81, 2018.

[6] J. Huo, Z. Li, L. Zhao, J. Liu, and Y. Xiao, "Dynamic behavior of carbon fiber-reinforced polymer-strengthened reinforced concrete beams without stirrups under impact loading," ACI Structural Journal, vol. 115, no. 3, pp. 775-787, 2018.

[7] X. Zhang and H. Hao, "Improved impact resistant capacity of segmental column with fibre reinforced polymer wrap," International Journal of Impact Engineering, vol. 125, pp. 117133, 2019.

[8] A. Abay and T. Wondimu, "Numerical investigation of bundled RC column under impact load," Advances in Civil Engineering, vol. 2021, 2021.

[9] D. S. Simulia, Abaqus 2017, Documentation, Dassault Systemes Waltham, MA, 2017.

[10] The European Standard EN 1992-1-1: 2004 Eurocode 2: Design of concrete Structures, British Standards Institution, BSI London, 2004.

[11] D. A. Hordijk and J. Heron, "Tensile and tensile fatigue behavior of concrete," Experiments, Modeling, and Analyses, vol. 37, no. 1, 1992.

[12] "Final draft," Model CEB-FIP Code, Vol. 1, Federation for Structural Concrete, , Lausanne, Switzerland, 2010.

[13] D. I. Kachlakev, T. H. Miller, T. Potisuk, S. C. Yim, and K. Chansawat, Finite Element Modeling of Reinforced concrete Structures Strengthened with FRP Laminates, Oregon. Dept. of Transportation. Research Group, United States, 2001.

[14] Z. Hashin, "Failure criteria for unidirectional fiber composites," Journal of Applied Mechanics, vol. 47, no. 2, pp. 329-334, 1980. 
[15] M. H. Kabir, S. Fawzia, T. H. T. Chan, and M. Badawi, "Numerical studies on CFRP strengthened steel circular members under marine environment," Materials and Structures, vol. 49, no. 10, pp. 4201-4216, 2016.

[16] T. Ngo, P. Mendis, A. Gupta, and Ramsay, "Blast loading and blast effects on structures-an overview," Journal of Structural Engineering, vol. 7, no. S1, pp. 76-91, 2007.

[17] L. J. Malvar and C. A. Ross, "Review of strain rate effects for concrete in tension," ACI Materials Journal, vol. 95, pp. 735-739, 1998.

[18] K. S. Long, M. Kasmuri, A. S. Zia Hasan, R. Hamid, and R. Hamid, "Dynamic increase factor of high strength concrete with silica fume at high strain rate loading," Materials Science Forum, vol. 857, pp. 299-304, 2016.

[19] A. M. Azrul and H. Hao, "Development of P-I diagrams for FRP strengthened RC columns," International Journal of Impact Engineering, vol. 38, no. 5, pp. 290-304, 2011. 